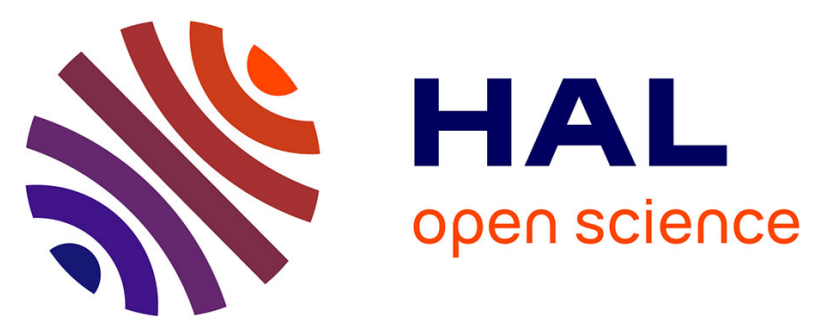

\title{
Mechanical restoration of gravity instabilities in the Brunei margin, N.W. Borneo
}

Josselin Berthelon, Xiaoping Yuan, Antoine Bouziat, Pauline Souloumiac, Manu Pubellier, Tristan Cornu, Bertrand Maillot

\section{To cite this version:}

Josselin Berthelon, Xiaoping Yuan, Antoine Bouziat, Pauline Souloumiac, Manu Pubellier, et al.. Mechanical restoration of gravity instabilities in the Brunei margin, N.W. Borneo. Journal of Structural Geology, 2018, 117, pp.148 - 162. 10.1016/j.jsg.2018.08.003 . hal-01912067

\section{HAL Id: hal-01912067 \\ https://hal-ifp.archives-ouvertes.fr/hal-01912067}

Submitted on 5 Nov 2018

HAL is a multi-disciplinary open access archive for the deposit and dissemination of scientific research documents, whether they are published or not. The documents may come from teaching and research institutions in France or abroad, or from public or private research centers.
L'archive ouverte pluridisciplinaire HAL, est destinée au dépôt et à la diffusion de documents scientifiques de niveau recherche, publiés ou non, émanant des établissements d'enseignement et de recherche français ou étrangers, des laboratoires publics ou privés. 


\section{Mechanical restoration of gravity instabilities in the Brunei margin, N.W. Borneo}

Josselin BERTHELON ${ }^{a,{ }^{*},}$, Xiaoping YUAN ${ }^{\mathrm{b}, * *},{ }^{\dagger}$, Antoine BOUZIAT ${ }^{\mathrm{c}}$, Pauline SOULOUMIAC $^{\mathrm{d}}$, Manu PUBELLIER ${ }^{\mathrm{e}}$, Tristan CORNU ${ }^{\mathrm{f}}$ and Bertrand MAILLOT ${ }^{\mathrm{g}}$

${ }^{a}$ Département Géosciences et Environnement (GEC), Université de Cergy-Pontoise,

Neuville-sur-Oise, France. Email address: josselin.berthelon@live.fr

${ }^{\mathrm{b}}$ Laboratoire de Géologie, Ecole Normale Supérieure, PSL Research University, Paris, France. Email address: xiaoping.yuan@gfz-postdam.de

${ }^{\mathrm{c}}$ IFP Energies nouvelles, 1 et 4 avenue de Bois-Préau, 92852 Rueil-Malmaison, France. Email address: antoine.bouziat@ifpen.fr

${ }^{\mathrm{d}}$ Département Géosciences et Environnement (GEC), Université de Cergy-Pontoise,

Neuville-sur-Oise, France. Email address: pauline.souloumiac@u-cergy.fr

éaboratoire de Géologie, Ecole Normale Supérieure, PSL Research University, Paris, France and

CNRS/UMR 8538, Paris, France.Email address: manupub.pubellier@gmail.com

${ }^{\mathrm{f}}$ Total SA, CSTJF, Avenue Larribau, Pau, France. Email address: tristan.cornu@total.com

'Département Géosciences et Environnement (GEC), Université de Cergy-Pontoise,

Neuville-sur-Oise, France. Email address: bertrand.maillot@u-cergy.fr

* Corresponding author: CREGU, Faculté des Sciences et Technologies, 1 boulevard des

Aiguillettes, 54501 Vandœuvre-lès-Nancy cedex, Tel: $+\mathbf{3 3 6 8 3 3 0 6 5 2 4 , ~ E m a i l ~ a d d r e s s : ~}$ josselin.berthelon@live.fr

${ }^{* *}$ Second corresponding author: Email address: xyuan@gfz-potsdam.de

\section{Keywords:}

- Gravity-driven deformations

- Mechanical restoration

- Fluids overpressure

- Mechanical modelling

- Brunei delta, Borneo

*Present address: GeoRessources (UMR 7359, Université de Lorraine/CNRS/CREGU), Vandœuvre-lèsNancy, France, and Total SA, CSTJF, Avenue Larribau, Pau, France.

†Present address: Helmholtz Centre Potsdam, German Research Center for Geosciences (GFZ), Potsdam, Germany 


\begin{abstract}
In offshore Brunei, the Baram delta displays Pliocene to recent gravitational deformations on top of the overpressured Setap Shales. We use the limit analysis, implemented in SLAMTec, to constrain their kinematics and propose first-order values of compatible pore pressures. Using the critical Coulomb wedge theory, we confirm that extreme overpressure are needed to account for the gravitational deformations currently observed in the delta. SLAMTec simulations quantify the role of the migration of the deltaic system on the deformations and suggest that this overpressure has existed since the initiation of the gravity-driven system. An inverse analysis is performed to identify the fluid overpressure and sedimentation pattern that best reproduces the forward structural model. This inverse approach validates the proposed kinematics, since we can reproduce quantities describing the structural style with overpressure coherent with the present-day observations. It points out the existence of key events explaining the structural interpretations, which leads to propose new kinematic models enriched with compatible pore pressure and sedimentation rates. This mechanical study highlights how mechanical modelling helps design a cross-section with an appropriate kinematics based on mechanical solutions and discuss on the basis of objective mechanical criteria the ranges of pore pressure consistent with a prescribed structural evolution.
\end{abstract}




\section{Introduction}

Gravity deformations in shelf edge deltas are defined by an upslope extensional domain (growth faults either synthetic or antithetic of the general displacements) and a downslope compressional domain (Fold and Thrust Belt (FTB)) [see review in Schultz-Ela, 2001; Rowan et al., 2004; Morley et al., 2011]. In the Champion-Baram delta, offshore Brunei, Pliocene to recent gravitational deformations are well-identified because of their major interest for the oil and gas industry [Sandal, 1996; Morley, 2003, 2009; Ingram et al., 2004]. While the kinematics of deformation is well-constrained in the Sabah FTB and the northern parts of offshore Brunei [e.g. Franke et al., 2008; Morley, 2009; Hesse et al., 2009, 2010; King et al., 2010; Sapin et al., 2011], more to the south the resolution of the published seismic images is insufficient to decipher the sequence of faults activities, in both extensional and compressional regions [Hesse et al., 2009; King et al., 2010; Sapin et al., 2011]. Without further geophysical and geological information, it is difficult to discriminate one among the different possible model of structural development, which lead to poorly constrain the burial, temperature and stress/strain history of each structural block [Sassi et al., 2007; Smart et al., 2012; Albertz \& Sanz, 2012; Albertz \& Lingrey, 2012; Berthelon \& Sassi, 2016]. Ultimately, it leads to uncertainties in petroleum system modelling, seals integrity analysis, pore pressure prediction and stress regime estimation, both because state-of-the-art basin modelling software use prescribed geometries at specific geological times that need prior structural validation [Neumaier et al., 2014; Faille et al., 2014; Thibaut et al., 2014; Burgreen-Chan et al., 2016], and because 2-D/3-D fully coupled hydromechanical numerical simulations are still unable to reproduce complex 2D/3D structural geometries [e.g. Couzens-Schultz \& Azbel, 2014; Obradors-Prats et al., 2016, 2017].

We evaluate specific points of the Brunei margin kinematics in terms of mechanical feasibility by requiring them to verify stress equilibrium and the Coulomb criterion for fluid-saturated rocks. We aim to combine mechanical solutions and structural interpretations to improve forward kinematic models, in the manner of Caër et al. [2015] and applied on the Brunei margin gravitational collapse system (GCS). We use the limit analysis theory, originally developed to predict the localisation of plastic deformation and plastic failure in civil engineering [e.g. 
Salençon, 2002]. The maximum strength theorem [Salençon, 2002; Maillot \& Leroy, 2006] corresponds to the kinematic approach of the limit analysis. It has been applied incrementally on compressive tectonics to determine the location and dip of the active ramp thrust and hinge planes at each shortening step, by optimization of the compressive tectonic force [Cubas et al., 2008] and further developed into the SLAMTec software (Sequential Limit Analysis Method for Tectonics [Mary et al., 2013a]). Pons \& Leroy [2012] accounted for the pore pressure in fluid saturated media. We use here the developments of Yuan et al. [2015, 2016] to account for extensional tectonics and gravitational deformations.

Gravity-driven deformations in shale-dominated deltas such as the Brunei margin are controlled by the strength of the clay-rich detachment that greatly depends on the magnitude of the pore fluid overpressure [Rowan et al., 2004; Morley et al., 2017, 2018], which itself depends on the stress/strain history, burial and temperature paths and the local fluid flows [Sassi et al., 2007; Beaudoin et al., 2014; Couzens-Schultz \& Azbel, 2014; Berthelon \& Sassi, 2016; Obradors-Prats et al., 2017]. Elevated overpressures are commonly observed in the Brunei margin [Morley, 2003; Tingay et al., 2009; Morley et al., 2011]. High overpressures within the detachment were shown theoretically and experimentally sufficient to initiate gravitational instabilities [Mourgues et al., 2009; Yuan et al., 2016; King \& Morley, 2017]. Differential loading by deltaic sedimentation between the delta plain and toe is also identified as a major triggering mechanism of gravity-driven deformations in many passive margins [Morley \& Guerin, 1996; Vendeville \& Cobbold, 1988; Rowan et al., 2004; Mourgues et al., 2009; Rouby et al., 2011; Morley et al., 2011]. Deltaic sedimentation is therefore one of the most important phenomenon, since it impacts (1) the differential loading and (2) the production of elevated overpressures through compaction processes and fluid expansion mechanisms such as kerogen to gas or clay transformations [e.g. Swarbrick et al., 2002]. Both quantities (i.e. fluid overpressure and deltaic sedimentation) are therefore important to consider jointly when attempting to design forward models of deformation validated by mechanical tools.

In this paper, we select a geological cross-section in the southern Brunei margin and describe its structural style, kinematics and boundary forces from up-to-date information available in 
the literature. We use the critical Coulomb wedge theory [Dahlen, 1984; Davis et al., 1983; Dahlen, 1990] developed for gravitational collapse with overpressured pore fluid [Dahlen, 1984; Xiao et al., 1991; Wang \& Hu, 2006; Mourgues et al., 2014; Yuan et al., 2015] to provide a first estimation of the pore pressure gradients and equivalent effective friction angles of the bulk and detachment materials, as in Bilotti \& Shaw [2005]; Yuan et al. [2016]; King \& Morley [2017]. Next, we use SLAMTec to determine the fluid overpressure along the bulk material and the detachment $\left(\Delta \lambda_{b}\right.$ and $\left.\Delta \lambda_{d}\right)$ and the progradation and aggradation of the Plio-Pleistocene deltaic sedimentation that reproduce best the forward structural model (designed according to the geological observations). We then point out the existence of unexpected but key structural and/or sedimentary events to explain the structural interpretations. Consequently, we propose two new kinematic models for the southern part of the Brunei margin, based respectively on variations of the sedimentary input, or on variations in the fluid overpressure found in the detachment.

\section{Geological settings}

\section{Tectonic and litho-stratigraphic context of the Brunei margin}

The offshore Champion-Baram basin forms the frontal part of the NW Borneo wedge (Figure 1). It is described as a gravity-driven FTB, associated with the deposition of two large postMid-Miocene deltas, the Baram Delta and the Champion Delta [Sandal, 1996; Ingram et al., 2004]. This basin is resting on a continental crust which records a complex accretionnary history resulting from the southward to south-eastward subduction of an early marginal basin, the Proto-South China Sea [Taylor \& Hayes, 2013; Rangin et al., 1999; Hall, 2013]. The beginning of the oceanic subduction is dated from the Middle Eocene [Tongkul, 1991], while the convergence zone evolved during the Middle Miocene into a collision zone [Tongkul, 1991; Hutchison et al., 2000; Cullen, 2010; Hutchison, 2010; Sapin et al., 2013]. This transition from oceanic subduction to collison is highlighted by the Mid-Miocene Unconformity (MMU) which forms a major regional unconformity. Continental subduction is thought to be active until the Early Pliocene, as the slab was breaking off [Rangin et al., 1999; Prouteau et al., 2001]. 
The Champion-Baram basin is formed by a thick pile $(>10 \mathrm{~km})$ of early Miocene to Recent clastic deposits, sourced from the rapid erosion of an uplifting mountain range forming in the north-eastern part of Borneo as a result of the subduction/collision [Morley, 2003; Sapin et al., 2013]. These sediments form a mainly prograding sequence of cyclic deltaic sand/shale deposits of tidal and shoreface facies [Sandal, 1996; Morley, 2003; Sapin, 2010]. They overlie a thick outer shelf/deep water prodelta shale sequence [Sandal, 1996; Sapin, 2010] usually known as the Setap Formation or Setap Shale (Figure 2b). This shale formation constitutes the main detachment level on which most of the gravity-driven deformations are localised (Figure 2c). This formation was deposited on top of a continental margin which may comprise horst and grabens that lead to lateral facies variations [Sapin, 2010; Sapin et al., 2011]. We consider that, at first order, the thickness of the formation lead to effectively decouple the deformation; This structural and stratigraphic heritage could have nonetheless impacted the subsequent deformations. The MidMiocene to Pliocene formations could be combined into a homogeneous pile of sediments, in which the Late Miocene Unconformity (LMU) seismic horizon marks the Miocene to Pliocene transition (Figure 2c).

The pore-pressure database compiled in the Champion-Baram basin [Tingay, 2003] indicates that overpressured formations are widespread in the area, both in the prodelta shales and the overlying deltaic sediments [Morley et al., 1998; Van Rensbergen et al., 1999; Morley, 2009; Tingay et al., 2009]. These overpressures strongly control the mechanical behaviour of the predominant sand/shale facies. Numerous mud volcanoes and shale diapirs highlight the ductile behaviour of the Setap Formation or synchronous shales formations, from the ChampionBaram delta to the Sabah FTB [Morley et al., 1998; Van Rensbergen et al., 1999; Sapin, 2010]. The considerable fluid overpressure measured in the basin have been linked to disequilibrium compaction in the prodelta shales [Tingay et al., 2009; Morley et al., 2014]. Tingay et al. [2009] suggest that much overpressure measured in the deltaic sequences have been vertically transferred from the prodelta shale via natural fractures and faults, which does not overruled the fact that fluid expansion mechanism like kerogen-to-gas maturation could have impacted the overpressure build-up, as demonstrated by Morley \& Guerin [1996]; Tingay et al. [2013] in 
other geological settings.

The Champion-Baram basin displays structural features typically associated with delta gravity tectonics (growth faults, mobile shale tectonics, toe thrusts) [Morley et al., 1998; Morley, 2003; Franke et al., 2008; Morley, 2009; Hesse et al., 2009, 2010; King et al., 2010; Morley et al., 2011; Sapin et al., 2011, 2012], while large scale thrusting and folding and inversion of growth faults reflect episodic phases of compressional tectonic [Sandal, 1996; Morley, 2003; Sapin et al., 2011, 2012]. The margin is characterized by NE to SW variation of the structural style [Cullen, 2010; Sapin, 2010; Sapin et al., 2011], mainly attributable to inherited NE-SW trending accretionary prism structures [Sapin et al., 2009, 2012]. In the north-eastern part of the basin, structural inheritance favours the formation of counter regional normal faults [Sapin et al., 2012], which are inverted in the inner part of the shelf [Morley, 2009; Sapin et al., 2012]. South-westward the paleo-accretionary prism front migrates toward the shelf and the counter regional normal faults tend to fade out in favour of a more conventional gravity-driven tectonic system defined by basin-ward oriented normal faults and toe thrusts (Figure 2c).

\section{Kinematics of the gravity-driven deformations in the southern part of the Brunei margin}

We selected a cross-section located in the southern part of the Brunei margin (Figure 2a, c). This cross-section has been interpreted by Sapin et al [2009] from a SE-NW seismic transect; a simple time to depth transformation has been applied, using a constant velocity to depth conversion referring to Morley et al. [2014]. The structural style of the southern part of the Brunei margin can be divided in three distinct provinces, from the SE to the NW (Figure 2c):

- The inverted province at the extreme SE edge of the section.

- The extensional province in the shelf, in which five major normal faults have been sequentially activated [Sapin et al., 2009; Sapin, 2010]. Three major kinematic steps are defined from the structural interpretation of Sapin et al. [2009]; Sapin [2010], establishing a prograding fault activity trend: a first phase sealed by the LMU seismic horizon, a second sealed by the Plioc1 seismic horizon, and a last phase active until recent times 
- The compression domain in the outer shelf, in which 6 fault-related folds totalize 4 to $9 \mathrm{~km}$ of shortening, as measured from the cross-section in Figure 2c. This wide range of shortening reflects uncertainties on the time to depth transformation. The structures are regularly spaced, with an average separation of $10 \mathrm{~km}$ between each consecutive fold crests. A precise timing of thrust activity has yet to be published, however several authors indicate that the faults are younger toward the distal parts of the delta as they approach the thrust front [Morley, 2009; Sapin et al., 2009; Sapin, 2010]. This in-sequence trend is observed regionally [Ingram et al., 2004; Morley, 2009; Sapin et al., 2011].

Recent works described a regional shortening amount in the delta toe that exceeds the amount of the shelf extension [Morley, 2003, 2009; Hesse et al., 2009; King et al., 2010; Cullen, 2010; Sapin et al., 2013], while upslope a compressive stress regime is computed from borehole failure analysis and inferred from the common observation of inverted growth faults [Tingay et al., 2009; King et al., 2010; Morley et al., 2011]. These authors refer to Pleistocene to recent plate-scale shortening across NW Borneo to explain these observations, possibly resulting from crustal-scale orogenic collapse mechanisms synchronous with the gravity-driven deltaic deformations [Sapin et al., 2013; Hall, 2013]. The extent of this crustal system, as described by Sapin et al. [2013], is indicated in Figure 1. This model suggests that part of the shortening recorded in the delta toe comes from the crustal-scale collapse system, added to the shortening linked with the collapse through additional displacements along the Setap Formation detachment or through inversion of inherited crustal structures below. This component of shortening adds a complexity in the Brunei margin collapse system with respect to the classical gravity-driven deformation model.

Figure 3 proposes a schematic evolution of the gravity-driven deformations since the deposition of the LMU, based on the stratigraphic evidences displayed in Figure 2c. Two main evolution steps are identified, linked with the development of two distinct gravitational collapse systems: GCS1 during the Pliocene and GCS2 during the Pleistocene. GCS1 is characterised by a major normal fault that transfers displacements toward two thrust-related folds (Figure 
3), which are formed in-sequence [Sapin et al., 2009; Sapin, 2010; Sapin et al., 2011]. This system overwrites Mio-Pliocene GCSs, sealed by the LMU; in fact the easternmost fold structure is likely inherited from this initial event, while being continuously reactivated during the Pliocene [Sapin et al., 2009; Sapin, 2010; Sapin et al., 2011]. The Plioc1 horizon seals this collapsing event. In the Pleistocene, the gravitational collapse system is displaced toward the delta toe, as the delta shelf-break is prograding (Figure 3). GCS2 is then localised along a major normal fault which accommodates more than $3 \mathrm{~km}$ of displacement, until recent times when the deformation is focused on a frontal secondary normal fault. The GCS2 event tilts the Late Pliocene GCS1 folded structures, and transfers shortening in the delta toe in which four in-sequence thrust-related folds are developed.

This kinematic model raises questions on the deformation processes that lead to the current structural geometry. First of all, one can ask if the strong fluid overpressure currently measured regionally in wells existed since the Late Pliocene, and were necessary to destabilise the margin despite the important deltaic sedimentation since the Miocene. Ultimately, our mechanical models would help refine the simple kinematic model proposed on Figure 3, by determining compatible values of fluid overpressure at each kinematic step and link all these kinematic steps with a coherent sedimentation model. The analytical and numerical mechanical analysis that are described in the following have been developed to investigate these questions, and especially:

- Provide first order values of fluid overpressure and effective friction angles of sediments that validate the proposed kinematic steps.

- Refine the kinematic model by proposing additional steps compatible with our mechanical analysis. 


\section{Mechanical methods}

\section{Static stability analysis of the southern Brunei margin using the critical Coulomb wedge theory}

We make use of the critical Coulomb wedge theory [Davis et al., 1983; Dahlen, 1984] developed for gravitational collapses with overpressured pore fluids [Dahlen, 1984; Xiao et al., 1991; Wang \& Hu, 2006; Mourgues et al., 2014; Yuan et al., 2015] to estimate the effective friction coefficients of the detachment $\left(\mu_{d}^{\prime}\right)$ and in the bulk material $\left(\mu_{b}^{\prime}\right)$ in the cross-section considered (Figure 2c). This work is similar to those of Bilotti \& Shaw [2005]; Suppe [2007]; Morley [2007]; Yuan et al. [2016]; King \& Morley [2017], among others, which apply the critical Coulomb wedge theory to various sedimentary wedges to discuss detachment strength and fluids overpressure conditions. Using the geometric parameters of the Brunei margin, deduced from the cross-section (Figure 2c), we explore the range of fluids overpressure conditions of the detachment and in the bulk compatible with the collapse currently observed in the Brunei wedge [e.g. Sandal, 1996; Morley, 2003; Tingay et al., 2009; Morley et al., 2011].

The introduction of fluids overpressure conditions in this static stability analysis is described in the following. We define the pore-fluid pressure $p$ and the overpressure $\Delta p$ (difference with the hydrostatic pressure) in a submerged wedge following Hubbert \& Rubey [1959]:

$$
p=g\left[\lambda \rho z+\left(\rho_{f}-\rho \lambda\right) D\right] \text { and } \Delta p=\Delta \lambda \rho g(z-D)
$$

at any depth $z$ counted positively from the sea surface. The sea bed is at depth $D$ from the sea surface. $g, \rho_{f}$, and $\rho$ are respectively the gravity acceleration, and the volumic masses of the water and of the fluid saturated sediments forming the wedge in $\mathrm{kg}^{-\mathrm{m}^{-3}}$. For the static approach (section 3), we define $\rho_{f}, \rho$ and $g=1000,2380$ and 9.81 respectively, and for the kinematic approach (section 4) we define $\rho_{f}, \rho$ and $g=1000,2400$ and 9.81 respectively. The two scalars $(\lambda)$ and $(\Delta \lambda)$ are respectively the fluid pressure ratio and the overpressure ratio, 
such that

$$
\Delta \lambda=\lambda-\lambda_{\text {hydro }}, \text { with } \lambda_{\text {hydro }}=\rho_{f} / \rho .
$$

$\lambda$ varies between $\rho_{f} / \rho$ and 1 , respectively in hydrostatic and lithostatic conditions, so that $\Delta \lambda$ varies between 0 and $1-\rho_{f} / \rho$. From this we define the effective friction coefficient $\mu^{\prime}$ and the corresponding friction angle $\phi^{\prime}$ as

$$
\mu^{\prime}=\mu *(1-\lambda) /\left(1-\lambda_{\text {hydro }}\right) \text { and } \phi^{\prime}=\arctan \left(\mu^{\prime}\right),
$$

where $\mu$ is the friction coefficient of the material in hydrostatic conditions.

In the critical Coulomb wedge theory, and throughout the present paper, the overpressure conditions are considered uniform in the bulk of the wedge. Therefore, only two values are required to define the pore pressure : $\Delta \lambda_{b}$ for the bulk material, and $\Delta \lambda_{d}$ for the detachment. Making the same assumption of uniformity for the friction parameters, we use the same subscripts $\phi_{b, d}, \mu_{b, d}$ and $\phi_{b, d}^{\prime}, \mu_{b, d}^{\prime}$.

\section{Sequential analysis of the southern Brunei margin gravitational collapse system using the SLAMTec method}

The theory of limit analysis provides a mathematical framework for (1) the analysis of the onset of structural events, such as a thrust or a gravitational collapse and (2) the long-term evolution of these geological structures, when sequentially combined with geometrical constructions of fault-related folds [see the review of Leroy \& Maillot, 2016]. The kinematic approach of limit analysis determines an upper bound to the values of tectonic forces by finding possible failure geometries [Salençon, 1974, 2002; Maillot \& Leroy, 2006; Leroy \& Maillot, 2016], and requires no rheology other than strength criteria (the Coulomb criterion). This upper bound depends on a virtual velocity field that corresponds to the tectonic movement. Optimization is achieved by selecting the scalars that parametrize this velocity fields as to minimize the upper bound and obtain the least upper bound [see the review of Leroy \& Maillot, 2016]. The failure mechanism associated to the least upper bound is said to be dominant, as its load cannot be exceed without 
triggering it. It has been shown that limit analysis reproduces and extends naturally the classical critical Coulomb wedge theory, while it also provides solutions for complex structural geometries and predictions for the localisation of the deformation [e.g. Cubas et al., 2008; Souloumiac et al., 2009; Mary et al., 2013a,b; Yuan et al., 2016; Leroy \& Maillot, 2016].

Yuan et al. [2015] have applied the kinematic approach of limit analysis to simulate gravitydriven deformations, and Yuan [2016]; Yuan et al. [2016] adapted the sequential version (called SLAMTec, for Sequential Limit Analysis Method for Tectonics, Mary et al. [2013a,b]) to follow gravitational collapses through time. Considering geological materials as overpressured Coulomb frictional material, SLAMTec is a forward method that detects at each increment of sedimentation a possible gravitational collapse (Figure 6). Optimal thrust and normal fault locations (respectively, the points G and J, Figure 6) and dips are determined using the maximum strength theorem [see Leroy \& Maillot, 2016, for a full explanation]. The basin geometry is then updated using geometrical rules that maintain the section volume constant, apart from the sedimentation input (Figure 6).

In the SLAMTec routine for gravitational collapse, the stability of the wedge is first analysed using limit analysis as developed by Yuan et al. [2015]. Depending on the results, two cases are possible (Figure 6):

- if the wedge is unstable, it is deformed incrementally by gravitational collapse until a new stable state is reached. While active, the faults undergo instant friction softening, promoting further collapses.

- if the wedge is stable, sedimentation is implemented according to three parameters (distal aggradation, proximal aggradation and progradation), which create a new topographic surface (Figure 6).

Appealing only to Coulomb frictional parameters, SLAMTec forward solutions are only dependent on sedimentation rates and are not dependent on any rheological sensitivity to strain rates. The modelling ends when the prescribed amount of sedimentation is reached.

In this work, SLAMTec is used to study the influence of the sedimentation and the fluid overpressure on the dynamics of the Brunei margin collapse. Assuming a constant detachment 
geometry through time, we design a prototype of the Brunei margin's geometry at the time of the LMU deposition from the structural interpretation of Sapin et al. [2009]; Sapin [2010], displayed in the cross-section Figure 2c. We propose ranges of values for the sedimentation parameters using the thickness of the sedimentary formation in the considered cross-section as a rough guide (Figure 2c). The results of the static stability analysis are used to reduce the explored parameters' space and predefine a range of effective friction coefficients compatible with gravity-driven deformations in the considered prototype. Gravity-driven deformation in this geological prototype is followed through time since the LMU deposition using SLAMTec and for different set of parameters. Effective friction coefficients and sedimentation parameters values that generate simulations matching best a set of objective geometric and kinematic criteria are then estimated using an inverse approach.

\section{Determination of the effective friction angles of the Brunei margin sediments using the critical Coulomb wedge theory}

We now apply the general formulation of the critical Coulomb wedge theory to the southern part of the Brunei wedge, using mean values of topographic and detachment slope angles measured on the cross-section Figure 2c. In Figure 4, critical limits are calculated using the critical Coulomb wedge theory, as a function of the topographic $(\alpha)$ and detachment $(\beta)$ slopes, for given bulk and detachment strengths and fluid overpressure. The entire limits are given in Figure $4 \mathrm{a}$ for $\phi_{b, d}=30^{\circ}$ and $20^{\circ}$ respectively, $\mu_{b, d}=0.577$ and 0.364 respectively and using $\lambda_{\text {hydro }}=0.42$. Setting $\Delta \lambda_{b}=0.31$ and $\Delta \lambda_{d}=0.57$ in equation (3), gives $\phi_{b}^{\prime}=15^{\circ}$ and $\phi_{d}^{\prime}=0.4^{\circ}$. The critical limits resulting from this calculation predict three states depending on the wedge geometry (Figure 4a): stable sliding on the detachment in the grey zone, compressive internal deformation along the dashed line (for $\beta \leq 3.5^{\circ}$ ), or gravitational collapse along the solid black line. In Figure 4b, we zoom around the region of interest (the mean $\alpha$ and $\beta$ values measured on the cross-section (Figure 2c)), and draw the envelopes for different values of $\phi_{d}^{\prime}$, each distinctly coloured. Most points are located around the critical limit for gravitational collapse for $\phi_{d}^{\prime} \approx 0.8^{\circ}$. It highlights that the recent collapsing movements observed in the 
Brunei margin imply very low effective friction values on the detachment, and therefore large fluid overpressure.

Figure 5 presents the critical limit in terms of $\phi_{b}^{\prime}$ and $\phi_{d}^{\prime}$ that destabilises the southern Brunei margin at its current geometry, fixing $\alpha$ and $\beta$ at $2^{\circ}$ and $1.8^{\circ}$ respectively. Analysis of the wedge state have been performed on 32 coupled values ranging from $10^{\circ}$ to $20^{\circ}$ for $\phi_{b}^{\prime}$, and from $0.2^{\circ}$ to $1.4^{\circ}$ for $\phi_{d}^{\prime}$, which correspond to $\Delta \lambda_{b, d}$ values ranging from 0.403 to 0.214 and from 0.574 to 0.541 , respectively. In Figure 5, each analysis is represented by a cross and is coloured with respect to calculated deformation state: light grey if the wedge is stable and dark grey if it is collapsing. Using these results, we can draw the critical limit between margin collapse and stability as function of $\phi_{b}^{\prime}$ and $\phi_{d}^{\prime}$, which follows a linear relationship (Figure 5). This critical limit seems to be almost independent from $\phi_{b}^{\prime}$, as a drop in friction of almost $10^{\circ}$ in the bulk is compensated by a drop of only $1^{\circ}$ in the detachment. As a result, independently of $\phi_{b}^{\prime}$ values, the critical limit for gravity collapse in the Brunei margin is defined for $\phi_{d}^{\prime}$ values ranging from 0.4 to $1.3^{\circ}$

This critical Coulomb wedge analysis highlights the overall stability of the southern Brunei margin geometry, as extreme fluid overpressure are needed to induce gravitational collapse. For example, assuming a value of $\phi_{b}^{\prime}$ of $10^{\circ}, \Delta \lambda_{d}$ must be up to 0.547 , which represents $94 \%$ of the lithostatic pressure at the detachment depth, to induce the collapse currently observed in the margin. However, this preliminary analysis has two limitations. First, the margin is represented by a perfect, infinite wedge, whereas the Brunei wedge is characterised by a surface and detachment topography. Second, this analysis only concludes on the stability of the margin at present-day with its current geometry. No clues are given on the localisation of the deformation, the geometry of the faults and their evolution and the role of surface processes. 


\section{Mechanical analysis of the Brunei margin gravitational collapse using Limit Analysis}

\section{Geological prototype}

\section{Geometry and boundary conditions}

Figure 7 sums up the boundary conditions used to model the southern Brunei margin using SLAMTec. The prototype geometry is inspired from the cross-section presented in Figure 2. The prototype extends over $160 \mathrm{~km}$ (Figure 7) from the front of the inverted province in the delta plain to the frontal limit of deformations in the delta toe. Topographic and detachment slope angles ( $\alpha_{1,2,3}$ and $\beta$ respectively) have been estimated from measurements on the cross-section (Figure 2c). We assumed that they are constant since the Pliocene and they are accordingly constant in our simulations. The lateral boundary conditions consist of fixed, undeformable walls (Figure 7). We thus neglect the regional far-field compression that impacted the structural evolution of the margin during the Plio-Pleistocene, and concentrate on the GCS.

\section{Mechanical parameters}

We recall that SLAMTec models are composed by only two types of materials: bulk and detachment, each described by a uniform friction coefficient, a fluid overpressure, and a volumic mass. We choose $\phi_{b}=30^{\circ}, \phi_{d}=10^{\circ}$ and $\lambda_{\text {hydro }}=0.417$ throughout the analysis, which are mean values describing the sediment rheology. We then let the overpressure $\Delta \lambda_{b, d}$ take values such that, according to (2) and (3), $\phi_{d}^{\prime}$ ranges from $0.05^{\circ}$ to $0.7^{\circ}$ and $\phi_{b}^{\prime}$, from $9^{\circ}$ to $15^{\circ}$. During their activities, normal faults and thrusts undergo friction softening which instantaneously drop their friction from $\phi_{b}=30^{\circ}$ to $\phi_{f}=1^{\circ}$, promoting further collapse at each incremental step. After slipping, when a stable state is recovered, the fault retrieves its initial friction $\left(\phi_{b}\right)$ instantaneously.

In the Brunei margin the prograding coarse-grained deltaic sandstones transitioned into fine-grained pro-delta shales toward the basin [e.g. Sandal, 1996]. In addition, the top of the pro delta shales also marks the top of main fluid overpressure [Tingay et al., 2009]. It 
potentially implies major mechanical property contrasts between the pro delta shale and the deltaic sandstone. However in the southern part of the Brunei margin, other detachment levels and disharmony only produce second-order structural features (Figure 2c), which suggest that they did not account for a large part of the shortening in this part of the margin. For that reason, we consider that simple prototypes with only two overpressured Coulomb frictional materials, the bulk and the detachment, should provide a reasonable description, i.e. not strongly biased, of the mechanical behaviour of the Brunei margin.

\section{Loading parameters: sedimentation}

Because no major regional erosion events are registered in the southern part of the basin during the Plio-Pleistocene [Morley, 2003; Sapin, 2010], we neglect erosion processes, and we describe the sedimentation acquired since the LMU at the Mio-Pliocene transition, 5.33 Ma ago with three lengths (Figure 7a):

- Proximal aggradation (PA): the thickness of aggrading sediments in the delta plain,

- Progradation (PROG): the horizontal displacement of the shelf-break, i.e. the point separating the delta plain and the delta slope,

- Distal aggradation (DA): the thickness of aggrading sediments in the delta toe.

These parameters can be roughly estimated on the cross-section in Figure 2c: $30 \mathrm{~km}$ of progradation, $3 \mathrm{~km}$ of proximal aggradation and $1.5 \mathrm{~km}$ of distal aggradation. However, (1) no decompaction correction have been applied, (2) consequent uncertainties exist on the time to depth conversion and the seismic interpretations and (3) local variations of the sediment thickness have also been observed over the basin [Van Rensbergen et al., 1999; Morley, 2003; Sapin, 2010]. Therefore, in our parametric exploration, we consider substantial variations around these values (Table 1).

Recalling that these lengths were acquired from the LMU to the present-day time, over a period of $5.33 \mathrm{Ma}$, the corresponding sedimentation rates are given in the last three columns of Table 1 . We also give the Thickness Ratio TR $=\mathrm{DA} / \mathrm{PA}$ in column 9 of Table 1 for further 
reference. All simulations were performed using 500 incremental steps (Figure 6), each step therefore corresponding to a time step of $5.33 \times 10^{6} / 499=10681$ years.

\section{Impact of the fluid overpressure and the sedimentation parameters on the evolution of the collapse within the prototype}

Before proceeding to a full parametric exploration in section 5.3, we first illustrate the effects of the mechanical and sedimentation parameters with the help of six simulations (S1 to S6, Table 1).

\section{Impact of the fluid overpressure conditions}

The final model geometry of S1 (Figure 8a) shows an extensional domain in the delta plain composed by several outcropping normal faults cumulating $3.9 \mathrm{~km}$ of slip over a region about $10 \mathrm{~km}$ wide. Most of the slip is accommodated through a major fault that develops a basin-ward half-graben. Six fault-related structures developed in the delta toe in response to the collapsing events. The faults (2) and (3) and the faults (4) and (5) are separated from each other by less than $2 \mathrm{~km}$ and we conclude that only four folds formed, each accommodating roughly the same amount of shortening and each fold's crest separated from the other by 5 to $10 \mathrm{~km}$.

The evolution of the position of the normal fault/thrust fault pair is given by the successive positions of the $\mathrm{J}$ and $\mathrm{G}$ points through time (Figure $6 \mathrm{~b}$ ), called a G-J gram following Mary et al. [2013a]. Between 5.33 Ma (beginning of the simulation) and 1.6 Ma, sediments accumulate at the prescribed rates and the margin remains stable. Progressively, the differential loading increases because PArate $>$ DArate, until the margin collapses at 1.6 Ma (Figure 8b). The margin remains strongly unstable and every second or third sedimentation step triggers additional gravitational collapse. Normal fault outcrops prograde with the shelf-break, while the local out-of-sequence thrusts (2) and (4) reactivate the earliest folded structures at $0.5 \mathrm{Ma}$ and 0 Ma respectively (Figure 8b).

In the next simulation (S2), $\phi_{d}^{\prime}$ is set to $0.15^{\circ}$ instead of $0.25^{\circ}$ (Table 1), reflecting an increase in the detachment overpressure. Destabilisation of the margin (Figure 9a) occurs earlier, at 
3.2 Ma, and exhibits $7 \mathrm{~km}$ of additional slip on the extensional domain. Both extensional and compressive zones are wider, with numerous out-of-sequence reactivations thrusting events (Figure 9b). Note that the normal faults position again prograde with the shelf-break; in fact this is a constant observation for any prescribed boundary conditions and mechanical parametrisation in our models.

\section{Impact of the sedimentation parameters}

Simulation S3 differs from S1 by an increased progradation of about 18\%(Table 1) that stabilises the margin (Figure 9b). We recall that the shelf-break progradation is performed conserving the topographic angles $\alpha_{1}, \alpha_{2}$ and $\alpha_{3}$ and with constant model length. Therefore at each sedimentation step the wedge thickness in the delta slope region is increased while the delta plain length is reduced. Taken together both effects (i.e. wedge thickness increase and delta plain length reduction) result in the margin stabilisation [Yuan, 2016; Yuan et al., 2016]. As such, when considering high values of PROGrate, the stabilisation of the margin can be considered as a boundary effect since it is, at least partly, linked with the initial length of the prototype.

In S4, PArate is increased by $\sim 40 \%$ to reach PArate $=0.66 \mathrm{~mm} \cdot \mathrm{y}^{-1}$ (Table 1$)$. The resulting simulation records numerous collapsing events (Figure 9c), which cumulate $17.2 \mathrm{~km}$ of displacements in the extensional zone. The collapse of the margin formed a thick extension zone aggregating multiple prograding normal faults. The large difference between PArate and DArate, highlighted by the low TR value (Table 1), puts the margin in a collapsing critical state as early as 3.8 Ma. Long-term collapse during the remaining 3.8 Ma results in the formation of a highly deformed compressive zone in the delta toe.

Simulations S5 and S6 have identical sedimentation parameters, except for DArates (with respective values DArate $=0.18 \mathrm{~mm} \cdot \mathrm{y}^{-1}$ and DArate $\left.=0.28 \mathrm{~mm} \cdot \mathrm{y}^{-1}\right)$, and using distinct $\phi_{d}^{\prime}$ values (Table 1) so that approximately $5.5 \mathrm{~km}$ of slip is cumulated along the normal faults of both simulations. The first observation is that, when DArate is increased by $\sim 40 \%$ (in S6), the value of $\phi_{d}^{\prime}$ must be increased to $0.7^{\circ}$ to reach similar cumulative slips values than in S5. Another way to tell is that more fluid overpressure are necessary in S5 to sufficiently 
lower the friction on the detachment level to reach similar values of collapse than in S6. In S5, the collapse of the margin starts at $2.7 \mathrm{Ma}$ and formed a narrow extension zone aggregating numerous normal faults. Thrusts are developed in two deformation phases: in-sequence until 1.6 Ma and then alternating out-of-sequence and in-sequence events until the simulation stops (Figure 9d). S6 displays a similar final geometry and evolution pattern (Figure 9e), except that the GCS is developed earlier and that a wider extension zone is formed. This last characteristic results from an increased time interval between two collapsing events than in S5, which is caused by the higher DArate value of S6. Another feature that is important to note is the propagation of the shortening front, which is strongly reduced in the S6 experiment compared to the S5 (Figure $9 \mathrm{c}$ and $\mathrm{d}$ ), which results from the higher sedimentation rate in the delta toe.

Note finally, that in some simulations (S2, S4, S5), the frontal thrusts seem to reach the end wall of the prototype, indicating that they would have been located further seaward, had the prototype been longer. We nevertheless keep the same prototype for the following inverse analysis. Indeed, such biased simulations are conflicting with the selection criteria, as we have verified a posteriori when analysing the inversion results.

\section{Inversion of effective friction and sedimentation parameters compatible with the observed gravitational collapses in the Brunei margin}

We conclude from the previous examples that our mechanical prototype of the Brunei margin can reproduce a GCS with realistic cumulative slip and map length. We now proceed to determine all the parameter values that yield simulations matching best the following four criteria, in inclusive order (Figure 10):

1. The margin is initially stable and collapses during the sedimentation.

2. The cumulative slip on the normal faults is between 4 and $9 \mathrm{~km}$; this large range results from uncertainties surrounding time-to-depth conversion and the structural interpretation.

3. The final length of the GCS (or GCSs) is equal to $100 \mathrm{~km}$.

4. Two distinct GCSs are formed sequentially. 
The ranges of values explored for each parameter are given in table 1, row "Param. study". Six values are selected for $\phi_{b}^{\prime}$, which range from $9^{\circ}$ to $14^{\circ}$ with a $1^{\circ}$ interval. Eleven values are selected for $\phi_{d}^{\prime}$, which range from $0.05^{\circ}$ to $0.7^{\circ}$ with a $0.05^{\circ}$ interval until $\phi_{d}^{\prime}=0.4^{\circ}$ and then a $0.1^{\circ}$ interval. Three values are selected for each sedimentation parameter, which are in terms of rates: PArate $=[0.47 ; 0.56 ; 0.65] m m . y^{-1}$, DArate $=[0.19 ; 0.28 ; 0.37] m m . y^{-1}$, PROGrate $=[4.7 ; 5.6 ; 6.4] m m . y^{-1} .1782$ simulations are required to treat each set of parameters thus defined.

All the simulations performed are shown in Figure 11 as crosses in $\left(\phi_{d}^{\prime}, \phi_{b}^{\prime}\right)$ graphs. Each graph corresponds to single values of PArate and PROGrate, and to three values of DArate. Therefore, each cross represents three simulations, for DArate $=0.19,0.28$ and $0.37 \mathrm{~mm} . \mathrm{y}^{-1}$. Crosses located above the oblique black line yield simulations that are unstable at the initial state, prior to sedimentation. They are discarded because they do not fit criterion 1 . The physical reason is that the effective friction angles are too low for the prototype to sustain itself without collapse. The unstable domain is only dependent on the initial prototype geometry and the values of $\phi_{d}^{\prime}$ and $\phi_{b}^{\prime}$. Therefore the black line is identically located in each graph of Figure 11. Conversely, crosses below a coloured solid line are simulations that remain stable throughout the sedimentation and are discarded by criterion 1 , because in those cases, the effective friction angles are too high for the margin to collapse, even when loaded by the total prescribed sedimentation. Criterion 1 is verified by simulations that have crosses located between the black line and the orange line (for DArate $=0.37 \mathrm{~mm} . \mathrm{y}^{-1}$ ), or purple line (for DArate $\left.=0.28 \mathrm{~mm} \cdot \mathrm{y}^{-1}\right)$, or blue line $\left(\right.$ DArate $\left.=0.19 \mathrm{~mm} \cdot \mathrm{y}^{-1}\right)$ : these simulations are initially stable and do collapse before the total prescribed amount of sedimentation is applied. For example, the set of parameters of S1 places the simulation in the collapse domain for DArate $=0.19 \mathrm{~mm} \cdot \mathrm{y}^{-1}$ (Figure 11a), implying the development of margin collapse during the sedimentation as observed in Figure 8. The same experiment but with DArate $=0.28 \mathrm{~mm} \cdot \mathrm{y}^{-1}$ (i.e. looking at the purple solid line) places the simulation in the stable domain (Figure 11a). These results show that even lower values of $\phi_{d}^{\prime}$ and $\phi_{b}^{\prime}$ than in the critical Coulomb wedge prototype (Figure 5) are necessary to trigger an instability. This is due to the stabilising role of the delta 
toe which does not exist in the critical Coulomb wedge prototype [Yuan et al., 2016].

The following trends for the sedimentation parameters appear from the comparison of the graphs in Figure 11:

- Increasing PArate moves in parallel the solid coloured lines to the right part of the graphs, that is the higher $\phi_{b}^{\prime}$ and $\phi_{d}^{\prime}$ regions. It means that more couples of $\phi_{b}^{\prime}$ and $\phi_{d}^{\prime}$ comprised in our search respect the criterion 1 when PArate is increased. For example, referring to DArate $=0.19$ mm. $y^{-1}$ (i.e. the blue solid line) in Figure 11b, the margin is stable for $\phi_{d}^{\prime}$ and $\phi_{b}^{\prime}$ fixed to $0.6^{\circ}$ and $10^{\circ}$ but it becomes unstable when PArate $\geq 0.56 \mathrm{~mm} . \mathrm{y}^{-1}$ (Figure 11b, c).

- Increasing DArate moves the solid coloured lines to the left part of the graphs, that is the lower $\phi_{b}^{\prime}$ and $\phi_{d}^{\prime}$ regions. It means that less couples of values $\left(\phi_{b}^{\prime}, \phi_{d}^{\prime}\right)$ comprised in our search respect the criterion 1 when DArate is increased. For example, in Figure 11a, fixing $\phi_{d}^{\prime}$ and $\phi_{b}^{\prime}$ at $0.25^{\circ}$ and $11^{\circ}$ respectively, the margin collapses for DArate $=$ $0.19 \mathrm{~mm} \cdot \mathrm{y}^{-1}$ while it remains stable for DArate $=0.28 \mathrm{~mm} \cdot \mathrm{y}^{-1}$.

- Increasing the PROGrate moves the solid coloured lines to the left part of the graphs, that is the lower $\phi_{b}^{\prime}$ and $\phi_{d}^{\prime}$ regions. Therefore PROGrate and DArate co-vary, even if PROGrate variation has less impact on the margin collapse.

Simulations represented by crosses located closer to the black "unstable initial state" line are characterized by the most cumulative slip, while these displacements decrease as crosses move closer to the corresponding coloured "collapse/stable limit" solid line. At the collapse/stable limit, simulations only display one gravitational collapse event, which results in 100 to $500 \mathrm{~m}$ of cumulative slip depending on the DArate value. The decrease follows a linear trend, which makes the cumulative slip values predictable. The explanation is that, with constant sedimentation parameters, increasing $\phi_{b}^{\prime}$ and $\phi_{d}^{\prime}$ postpones proportionaly the triggering of the margin instability. From the moment that the critical state is achieved, gravitational collapse occurs at almost every sedimentation step. Therefore cumulative slip is greater when collapse happens earlier, and as such when $\phi_{b}^{\prime}$ and $\phi_{d}^{\prime}$ are lower. 
An important lesson highlighted by the Figure 11 is that, independently from $\phi_{b}^{\prime}$ and $\phi_{d}^{\prime}$ values, the cumulative slip computed in our simulations are dependent on the relative values of DArate and PArate, expressed by the TR value. As TR increases, meaning as DArate increases compared to PArate, the critical limit for gravity collapse moves towards lower $\phi^{\prime}$ domains (see, for example, the respective positions of the coloured solid lines in Figure 11a, b, c with respect to their TR values), which indicates that higher fluid overpressure are necessary to create the conditions for gravitational instabilities. This was also described in the comparison between the S5 and S6 experiments.

The simulations that fit the criterion 2 are shown as coloured bands delimited by dashed lines in Figure 11. The inferior limit of the bands, that is the one closer to the solid coloured line, corresponds to simulations displaying $4 \mathrm{~km}$ of cumulative slip, while the superior limit (the one closer to the solid black lines) corresponds to simulations displaying $9 \mathrm{~km}$ of cumulative slip. The evolution of the cumulative slip between these too values limiting our search is linear. The band envelopes isolate a total of 86 simulations where the cumulative slip is comprised between 4 and $9 \mathrm{~km}$. It should be noted that the envelopes shrink with increasing TR (see for example the different envelopes in Figure 11f). Because cumulative slip is close to zero at the solid coloured lines and maximum at the solid black lines, and because with increasing TR the solid coloured lines are moved closer to the solid black lines, for higher TR values the linear coefficients of the cumulative slip vs $\phi^{\prime}$ values relationships is increased. It means that at each increment of $\phi^{\prime}$ the cumulative slip is increased further when TR is higher. The result is that with higher TR values the range of experiments that respect the criterion 2 is reduced, until becoming virtually close to zero, as seen for instance when $\mathrm{TR}=0.67$ in Figure $11 \mathrm{~b}$.

Simulations fitting the criterion 3 are shown as bold crosses. Only 14 simulations are characterised by a final GCS length smaller than $105 \mathrm{~km}$. S6 (Figure 9e) is an example of one of these (Figure 11b). Simulations that respect criterion 3 have systematically a TR value superior to 0.5 (Figure 11); high values of DArate compared to PArate are indeed needed to limit the propagation of the deformation to $100 \mathrm{~km}$, as explained comparing S5 and S6 (Figure $9 \mathrm{~d}, \mathrm{e})$. 
The 14 remaining simulations define the most realistic set of parameters. The range of values for these successful simulations is determined as follows: $\phi_{d}^{\prime}=[0.1-0.5]^{\circ}, \phi_{b}^{\prime}=[9-12]^{\circ}$ and a TR value superior to 0.5. In Figure 12, the final geometry of one of these best-fit examples (S7 in Figure 11e, with DArate $\left.=0.28 \mathrm{~mm} \cdot \mathrm{y}^{-1}\right)$ is compared with the geological cross-section . The sedimentation progressively builds up the margin until it reaches a critical point marking the start of its gravitational collapse (Figure 12a). The first steps of these collapse events are characterized by the formation of 5 in-sequence thrusts, that define 5 folds. Starting at 1.9 Ma, out-of-sequence thrusts reactivate previous fold structures as newly formed fold deformed the most distal regions. At the final stage of sedimentation, the collapse becomes progressively focused on a single normal fault creating an important depocenter (Figure 12c). Deformation in the compressive region is diffuse, characterised by seven consecutive fold structures formed by eleven thrusts spread over $30 \mathrm{~km}$. The position and size of the extension and compression regions are similar in both the simulation and the geological cross-section

Criterion 4 was missed by all the simulations. One GCS formed if any, because sedimentation rates and effective frictions were kept constant in each simulation. We show in the next section that a single change in the basal effective friction can produce a temporary arrest of the current GCS, followed by a new GCS frontward.

\section{Improved parametrisation of the Brunei margin}

As seen above, even in our best simulations, the subsidence in the delta plain is spatially distributed instead of forming two GCS's with distinct blocks separated by normal faults. To remedy this discrepancy we let the detachment effective friction angle increase during the sedimentation. S8 is identical to S7, except that the value of $\phi_{d}^{\prime}$ starts at $\phi_{d}^{\prime}=0.25^{\circ}$. In Figure 11 , it corresponds to the starting point of the simulation defined by $\phi_{d}^{\prime}=0.25^{\circ}, \phi_{b}^{\prime}=10^{\circ}$ and DArate $=0.28 m m \cdot y^{-1}$. A GCS forms after one sedimentation step (Figure 13, blue lines and crosses) and it is stopped by increasing $\phi_{d}^{\prime}$ to $0.35^{\circ}$ at 4.4 Ma. Sedimentation then continues, the delta progrades without collapse nor internal deformation and seals GCS1 until the Plioc1 deposits (Figure 13b). This stable phase displaces the shelf break toward the delta toe until, at 
2.7 Ma, the margin becomes unstable again and creates a second GCS in front of the first one (Figure 13b, red lines and crosses). As a result, the final geometry of the cross-section is better simulated, as criterion 4, i.e. the occurrence of two distinct GCS's is now verified (Figure 13c). Note that the total cumulative slip on the normal faults comprising the two successive GCSs is $5 \mathrm{~km}$, which still satisfies the second criteria.

Other models could be designed to respect the fourth criterion. For example by letting the sedimentation parameters vary rather than the friction properties. The selection between sedimentation or fluid overpressure variations must be made in accordance with geological information that is still lacking.

\section{Redrawing the Plio-Pleistocene kinematics}

Overall the modelling results validate mechanically the kinematic evolution presented in Figure 3, because they can reproduce the occurrence, slip magnitude, and total length of the GCS (criteria 1, 2, 3) using mechanical and sedimentation parametric ranges compatible with the present-day geological observations. The ranges of the effective friction angles are $9^{\circ} \leq \phi_{b}^{\prime} \leq 12^{\circ}$ and $0.1^{\circ} \leq \phi_{d}^{\prime} \leq 0.5^{\circ}$. Using equations (1), (2) and (3) and Table 1, these give pore pressure values between 59 and $62 \mathrm{MPa}$ along the detachment in the thrusting region of the delta toe. These values can be compared to pressure data available in Tingay [2003] for three neighbouring wells in the thrusting region (Ketambak 1, Z1-1 and Parak-1), among which are repeated formation tester data, the static mudweigth, leak off pressures and fracture closure pressures. These data highlight a significant fluid overpressure window drilled from $2500 \mathrm{~m}$ to $3000 \mathrm{~m}$ below the sea surface, which corresponds to the top of the pro-delta shales. It gives a maximum pressure gradient estimated between $16 \mathrm{MPa} / \mathrm{km}$ and $18 \mathrm{MPa} / \mathrm{km}$, which is in accordance with the $19 \mathrm{MPa} / \mathrm{km}$ to $20 \mathrm{MPa} / \mathrm{km}$ gradients found at deeper levels in our models.

Figure 11 could in the same manner be transferred into pore-pressure maps at any depth and any geological time defining the minimum pore pressure needed for the geological system to collapse, and jointly the maximum pore pressure for the geological system to remain stable. These quantities provide useful guidelines to validate basin modelling results where pore-pressure is 
calculated using prescribed structural geometries [e.g. Neumaier et al., 2014; Burgreen-Chan et al., 2016], as they provide the end-member pore-pressure values beyond which the prescribed kinematics become mechanically unrealistic.

Our modelling approach failed to produce two distinct GCSs (criterion 4), and this suggests the occurrence of an external event during the margin evolution, that was not accounted for in our modelling since we used constant parametric values throughout the simulations. We propose two hypotheses validated by the SLAMTec approach for this event :

- Variations of accomodation space in the basin during the Pliocene, which manifest itself as variations in the PArate and PROGrate. This model refers to external factors, most likely linked with the slab break-off and crustal rebound in Borneo during the Pliocene.

- Decrease in the fluid overpressure state within the post-Miocene sediments, consequently to a major fluid discharge event. This model refers to internal factors, linked with dynamic variations of the Setap Shales permeability, most likely a consequence of the lithostatic fluid overpressure in the sedimentary formation lasting from the Neogene to Recent time.

Note that other processes can be considered to explain these shifts in depocentres (that are common features of delta systems), such as: (1) growth fault strain hardening due to depletion of the weak layer (i.e. a weld develops), or (2) overpressure is locally depleted from beneath the depocentre, or (3) sedimentation rates are such that a single faults cannot displace fast enough to accommodate all the sediments and another depocentre develops simultaneously. Since SLAMTec current implementation does not have these mechanisms properly built into it, it de facto excluded them from our hypotheses. That said, it does not exclude the validity of the two models proposed above, but reinforce the fact that they must be considered as end-member structural solutions.

We now redraw the schematic geological scenario presented in Figure 3 taking into account the inversion results in terms of fluid overpressure and sedimentation patterns, inspired by each end-member hypothesis proposed for the development of the two subsequent GCSs (Figure 14).

In the first end-member model (Figure 14a), the fluid overpressure gradient is fixed so that $\phi_{d}^{\prime}=0.25^{\circ}$ and $\phi_{b}^{\prime}=10^{\circ}$. We make the assumption that the distal aggradation is constant as well 
as the sediment fluxes. After the LMU deposit, the delta is characterized by a prograding delta sequence, which is conjugated with low aggradation rate in the delta plain (Figure 14a). Results of the inversion available in Figure 11 confirm the stability of the margin for such sedimentation model and fluid overpressure values. This sequence is followed by an important aggradation phase, lasting until the Late Pliocene, which tends to destabilise the margin. According to the inversion table (Figure 11), it leads to the formation of the first GCS, creating two large thrust-related folds which are formed simultaneously. During the Late Pliocene, the delta is again marked by an important progradation phase, which leads to a second stabilisation period that contributes to greatly move the shelf break toward the delta front. The Pleistocene period marks a second phase of delta aggradation, which contributes to form the second GCS. Four thrust-related folds are formed principally in-sequence, with occasionally out-of-sequence reactivations.

The second end-member proposition (Figure 14b) is a direct transcription of the model results shown in Figure 13. The deltaic growth is assumed to be regular during the PlioPleistocene, while being particularly important due to the rapid uplift of Borneo since the slab break-off in the early Pliocene. The high fluid overpressure in the detachment layer, consecutive of the deposit of large volumes of sediment on top of the low permeability Setap shales since the Miocene, is responsible for the formation of the early GCS. The reduction of fluid overpressure gradients within the detachment layers would then stabilise the margin until the Late Pliocene. While counter-intuitive, fluid overpressure drops could indicate the fracturation of the shales layers, leading to fluids discharge and the regional increase in the seal permeability. The continued sedimentation of the delta would then progressively drive the margin back to gravitational instability, leading to the formation of the second GCS during the end of the Pliocene and the Pleistocene-Recent times.

The two end-member kinematic scenarios (Figure 14) still need important back-up from a refined geologic study of the area to be validated. The set-up, mechanics and loading parameters we applied in our models are sensibly simplified from regional geology, and therefore the implementation of additional controlling parameters in SLAMTec (such as a more com- 
plex sedimentation model, inherited faulted structures, detachment dips variations in space and time and/or basement subsidence) could lead to supplementary models for the sequential development of the GCSs. Still, the two proposed scenarii can be used as guidelines to define the missing data needed to propose refined structural kinematic solutions of the southern Brunei margin; notably the sequence stratigraphic framework of the Plio-Pleistocene in the cross-section area (i.e. the migration of the sedimentary system) and the search for clues helping to describe the fluids flows in the fractured state and cements of the Setap shales and the above stratigraphy (as in Gasparrini et al. [2014]; Beaudoin et al. [2014] for instance).

\section{Conclusion}

We consider the development of large scale Gravitational Collapse Systems (GCS) offshore NW Brunei that are resulting from massive sediment influxes of the large post-mid-Miocene Baram and Champion deltas. Since the Pliocene (5.33 Ma), due to the differential sediment loading between the delta plain and the seaward deep basin, many large normal faults formed in the plain ground. The consecutive seaward displacement occured down to the Setap shale formation (Lower Miocene) acting as the major detachment level transferring extension in the plain into a compressive fold-and-thrust belt at the delta toe. Overall, the GCSs are more than a hundred $\mathrm{km}$ wide in cross-section, with 4 to $9 \mathrm{~km}$ of cumulative slip on the normal faults.

Our aim is to validate and refine this scenario with the help of mechanical concepts (equilibrium, Coulomb criterion and a part of Limit Analysis called the maximum strength theorem), and to thus constrain the compatible mechanical parameter ranges.

The present day cross-section exhibits a low taper between the surface topography and the detachment that implies, according to the critical Coulomb wedge theory, a low effective friction angle in the bulk $\left(10^{\circ}\right.$ to $\left.20^{\circ}\right)$ and a very low one in the detachment $\left(0.2^{\circ}\right.$ to $\left.1.8^{\circ}\right)$, assuming that the GCS are currently in a critical state of activation.

Next, we use the maximum strength theorem with the SLAMTec software that allows us to simulate the evolution of the GCSs since the Pliocene using only a few parameters: sedimentation rates, bulk and detachment friction angles, and pore pressure profiles. The numerical 
efficiency of this semi-analytic method allows us to explore the parametric space with nearly 2000 simulations and to determine the parameter ranges that reproduce the occurrence of GCS, their total cross-section width, and the cumulative slip on the normal faults. In doing so, we found a narrower range of effective friction angles: from $9^{\circ}$ to $12^{\circ}$ in the bulk and from $0.1^{\circ}$ to $0.5^{\circ}$ in the detachment. The high fluid overpressures explaining these low effective strengths should have been occurring since at least the LMU deposits during the Pliocene to respect the present-day structural observations. However, no simulation reproduced the formation of the two prograding sequences of GCS observed in the seismic data. This discrepancy points to a major change in either one of the main controlling factors of the collapse: the sedimentary migration of the delta, or changes in the pore pressure magnitudes. Based on this, we propose two qualitative structural scenarii, with estimations of the variations in sedimentation rates or in pore overpressures that could be responsible for the change of active GCS during the Pliocene.

These mechanical analyses confirm the overall kinematic evolution of the cross-section, demonstrating its mechanical feasibility for parameter values that fall within the range of the geological observations. They illustrate how mechanical modelling can be used in a practical way to help design a cross-section with an appropriate structural style and kinematics based on mechanical solutions. As in the work of Caër et al. [2015], we show that it is important to account for the topography and the frictional resistance of overpressured sediments or, in other words, to account for the material weight and finite strength when designing a cross-section. Such modelling exercises are useful to prepare the ground for more advanced thermo-fluid structural scenarii, as proposed in the works of Neumaier et al. [2014]; Faille et al. [2014]; Thibaut et al. [2014]; Burgreen-Chan et al. [2016]; Obradors-Prats et al. [2017].

\section{Acknowledgement}

The authors are grateful to Total S.A. and IFPEN for the post-doctoral grant of Josselin Berthelon. Baptiste Mary is thanked for his help handling and developing the SLAMTec software. This work also benefited from helpful discussion with Marie-Christine Cacas-Stentz and Nicolas 
Guy. Reviewer C.Morley is thanked for his constructive comments.

\section{References}

Albertz, M, \& Lingrey, S. 2012. Critical state finite element models of contractional fault-related folding: Part 1. Structural analysis. Tectonophysics, 576, 133-149.

Albertz, M, \& Sanz, PF. 2012. Critical state finite element models of contractional fault-related folding: Part 2. Mechanical analysis. Tectonophysics, 576, 150-170.

Beaudoin, Nicolas, Lacombe, Olivier, Bellahsen, Nicolas, Amrouch, Khalid, \& Daniel, Jean-Marc. 2014. Evolution of pore-fluid pressure during folding and basin contraction in overpressured reservoirs: insights from the Madison-Phosphoria carbonate formations in the Bighorn Basin (Wyoming, USA). Marine and Petroleum Geology, 55, 214-229.

Berthelon, Josselin, \& Sassi, William. 2016. A discussion on the validation of structural interpretations based on the mechanics of sedimentary basins in the northwestern Mediterranean fold-and-thrust belts. Bulletin de la Société géologique de France, 187(2), 83-104.

Bilotti, Frank, \& Shaw, John H. 2005. Deep-water Niger Delta fold and thrust belt modeled as a critical-taper wedge: The influence of elevated basal fluid pressure on structural styles. $A A P G$ Bulletin, 89(11), 1475-1491.

Burgreen-Chan, Blair, Meisling, Kristian E, \& Graham, Stephan. 2016. Basin and petroleum system modelling of the East Coast basin, New Zealand: a test of overpressure scenarios in a convergent margin. Basin Research, 28(4), 536-567.

Caër, Typhaine, Maillot, Bertrand, Souloumiac, Pauline, Leturmy, Pascale, de Lamotte, Dominique Frizon, \& Nussbaum, Christophe. 2015. Mechanical validation of balanced cross-sections: The case of the Mont Terri anticline at the Jura front (NW Switzerland). Journal of Structural Geology, 75, 32-48.

Couzens-Schultz, Brent A, \& Azbel, Konstantin. 2014. Predicting pore pressure in active fold-thrust systems: An empirical model for the deepwater Sabah foldbelt. Journal of Structural Geology, 69, 465-480. 
Cubas, N, Leroy, YM, \& Maillot, B. 2008. Prediction of thrusting sequences in accretionary wedges. Journal of Geophysical Research: Solid Earth, 113(B12).

Cullen, Andrew B. 2010. Transverse segmentation of the Baram-Balabac Basin, NW Borneo: refining the model of Borneo's tectonic evolution. Petroleum Geoscience, 16(1), 3-29.

Dahlen, F. A. 1984. Noncohesive critical Coulomb wedges: An exact solution. Journal of Geophysical Research: Solid Earth, 89(B12), 10125-10133.

Dahlen, F.A. 1990. Critical Taper Model of Fold-and-Thrust Belts and Accretionary Wedges. Annual Review of Earth and Planetary Sciences, 18, 55.

Davis, Dan, Suppe, John, \& Dahlen, F. A. 1983. Mechanics of fold-and-thrust belts and accretionary wedges. Journal of Geophysical Research: Solid Earth, 88(B2), 1153-1172.

Faille, Isabelle, Thibaut, Muriel, Cacas, M-C, Havé, Pascal, Willien, Françoise, Wolf, Sylvie, Agélas, Léo, \& Pegaz-Fiornet, Sylvie. 2014. Modeling fluid flow in faulted basins. Oil \& Gas Science and Technology-Revue d'IFP Energies nouvelles, 69(4), 529-553.

Franke, Dieter, Barckhausen, Udo, Heyde, Ingo, Tingay, Mark, \& Ramli, Nordin. 2008. Seismic images of a collision zone offshore NW Sabah/Borneo. Marine and Petroleum Geology, 25(7), 606-624.

Gasparrini, Marta, Sassi, William, \& Gale, Julia FW. 2014. Natural sealed fractures in mudrocks: A case study tied to burial history from the Barnett Shale, Fort Worth Basin, Texas, USA. Marine and Petroleum Geology, 55, 122-141.

Hall, Robert. 2013. Contraction and extension in northern Borneo driven by subduction rollback. Journal of Asian Earth Sciences, 76, 399 - 411.

Hesse, S, Back, S, \& Franke, D. 2009. The deep-water fold-and-thrust belt offshore NW Borneo: Gravity-driven versus basement-driven shortening. Geological Society of America Bulletin, 121(56), 939-953.

Hesse, S, Back, S, \& Franke, D. 2010. The structural evolution of folds in a deepwater fold and thrust belt-a case study from the Sabah continental margin offshore NW Borneo, SE Asia. Marine and Petroleum Geology, 27(2), 442-454. 
Hubbert, King M, \& Rubey, William W. 1959. Role of fluid pressure in mechanics of overthrust faulting: I. Mechanics of fluid-filled porous solids and its application to overthrust faulting. Geological Society of America Bulletin, 70(2), 115-166.

Hutchison, Charles S. 2010. Oroclines and paleomagnetism in Borneo and south-east Asia. Tectonophysics, 496(1-4), 53-67.

Hutchison, Charles S, Bergman, Steven C, Swauger, David A, \& Graves, John E. 2000. A Miocene collisional belt in north Borneo: uplift mechanism and isostatic adjustment quantified by thermochronology. Journal of the Geological Society, 157(4), 783-793.

Ingram, G.M, Chisholm, T.J, Grant, C.J, Hedlund, C.A, Stuart-Smith, P, \& Teasdale, J. 2004. Deepwater North West Borneo: hydrocarbon accumulation in an active fold and thrust belt. Marine and Petroleum Geology, 21(7), 879 - 887. Oil and Gas in Compressional Belts.

King, Rosalind C, \& Morley, Chris K. 2017. Wedge geometry and detachment strength in deepwater fold-thrust belts. Earth-science reviews, 165, 268-279.

King, Rosalind C, Backé, Guillaume, Morley, Christopher K, Hillis, Richard R, \& Tingay, Mark RP. 2010. Balancing deformation in NW Borneo: Quantifying plate-scale vs. gravitational tectonics in a delta and deepwater fold-thrust belt system. Marine and Petroleum Geology, 27(1), 238-246.

Leroy, YM, \& Maillot, B. 2016. Mechanics of Accretionary Prisms and Fold-and-Thrust Belts Based on Limit Analysis. Pages 1-50 of: Advances in Geophysics, vol. 57. Elsevier.

Maillot, Bertrand, \& Leroy, Yves M. 2006. Kink-fold onset and development based on the maximum strength theorem. Journal of the Mechanics and Physics of Solids, 54(10), 2030 - 2059.

Mary, Baptiste CL, Maillot, Bertrand, \& Leroy, Yves M. 2013a. Predicting orogenic wedge styles as a function of analogue erosion law and material softening. Geochemistry, Geophysics, Geosystems, 14(10), 4523-4543.

Mary, B.C.L., Maillot, B., \& Leroy, Y.M. 2013b. Deterministic chaos in frictional wedges revealed by convergence analysis. International Journal for Numerical and Analytical Methods in Geomechanics, 37(17), 3036-3051.

Morley, Chris K. 2009. Growth of folds in a deep-water setting. Geosphere, 5(2), 59-89. 
Morley, Chris K, Warren, John, Tingay, Mark, Boonyasaknanon, Phathompat, \& Julapour, Ali. 2014. Reprint of: Comparison of modern fluid distribution, pressure and flow in sediments associated with anticlines growing in deepwater (Brunei) and continental environments (Iran). Marine and petroleum geology, 55, 230-249.

Morley, CK. 2003. Mobile shale related deformation in large deltas developed on passive and active margins. Geological Society, London, Special Publications, 216(1), 335-357.

Morley, C.K. 2007. Interaction between critical wedge geometry and sediment supply in a deep-water fold belt. Geology, 35(2), 139-142.

Morley, CK, \& Guerin, G. 1996. Comparison of gravity-driven deformation styles and behavior associated with mobile shales and salt. Tectonics, 15(6), 1154-1170.

Morley, CK, Crevello, P, \& Ahmad, Zulkifli Haji. 1998. Shale tectonics and deformation associated with active diapirism: the Jerudong Anticline, Brunei Darussalam. Journal of the Geological Society, 155(3), 475-490.

Morley, CK, King, R, Hillis, R, Tingay, Mark, \& Backe, G. 2011. Deepwater fold and thrust belt classification, tectonics, structure and hydrocarbon prospectivity: A review. Earth-Science Reviews, 104(1-3), 41-91.

Morley, CK, von Hagke, C, Hansberry, RL, Collins, AS, Kanitpanyacharoen, W, \& King, R. 2017. Review of major shale-dominated detachment and thrust characteristics in the diagenetic zone: Part I, meso-and macro-scopic scale. Earth-Science Reviews, 173, 168-228.

Morley, CK, von Hagke, C, Hansberry, R, Collins, A, Kanitpanyacharoen, W, \& King, R. 2018. Review of major shale-dominated detachment and thrust characteristics in the diagenetic zone: Part II, rock mechanics and microscopic scale. Earth-Science Reviews.

Mourgues, R, Lecomte, E, Vendeville, B, \& Raillard, S. 2009. An experimental investigation of gravitydriven shale tectonics in progradational delta. Tectonophysics, 474(3-4), 643-656.

Mourgues, R., Lacoste, A., \& Garibaldi, C. 2014. The Coulomb critical taper theory applied to gravitational instabilities. Journal of Geophysical Research: Solid Earth, 119(1), 754-765. 2013JB010359. 
Neumaier, Martin, Littke, Ralf, Hantschel, Thomas, Maerten, Laurent, Joonnekindt, Jean-Pierre, \& Kukla, Peter. 2014. Integrated charge and seal assessment in the Monagas fold and thrust belt of Venezuela. AAPG bulletin, 98(7), 1325-1350.

Obradors-Prats, J, Rouainia, M, Aplin, AC, \& Crook, AJL. 2017. Hydromechanical Modeling of Stress, Pore Pressure, and Porosity Evolution in Fold-and-Thrust Belt Systems. Journal of Geophysical Research: Solid Earth, 122(11), 9383-9403.

Obradors-Prats, Joshua, Rouainia, Mohamed, Aplin, Andrew C, \& Crook, Anthony JL. 2016. Stress and pore pressure histories in complex tectonic settings predicted with coupled geomechanicalfluid flow models. Marine and Petroleum Geology, 76, 464-477.

Pons, A., \& Leroy, Y.M. 2012. Stability of accretionary wedges based on the maximum strength theorem for fluid-saturated porous media. Journal of the Mechanics and Physics of Solids, 60(4), $643-664$.

Prouteau, G, Maury, RC, Pubellier, M, Cotten, J, \& Bellon, H. 2001. Post-Collisional Magmatism from NW Borneo: Evidence for Melting of an Oceanic Crust Deliver within the Upper Mantle. Bulletin de la Societe Geologique de France, 172(3), 319-332.

Pubellier, M., Savva, D., Aurelio, M., \& Sapin, F. 2017. Structural Map of the South China Sea; scale 1:3M. Commission for the Geological Map of the World.

Rangin, C., Le Pichon, X., Mazzotti, S., Pubellier, M., Chamot-Rooke, N., Aurelio, M., Walpersdorf, Andrea, \& Quebral, R. 1999. Plate convergence measured by GPS across the Sundaland/Philippine Sea Plate deformed boundary: the Philippines and eastern Indonesia. Geophysical Journal International, 139(2), 296-316.

Rouby, Delphine, Nalpas, Thierry, Jermannaud, Paul, Robin, Cécile, Guillocheau, François, \& Raillard, Stéphane. 2011. Gravity driven deformation controlled by the migration of the delta front: the Plio-Pleistocene of the Eastern Niger Delta. Tectonophysics, 513(1-4), 54-67.

Rowan, Mark G, Peel, Frank J, \& Vendeville, Bruno C. 2004. Gravity-driven fold belts on passive margins.

Salençon, Jean. 1974. Théorie de la plasticité pour les applications à la mécanique des sols. 
Salençon, Jean. 2002. De l'élasto-plasticité au calcul à la rupture. Editions Ecole Polytechnique.

Sandal, Svein T. 1996. The geology and hydrocarbon resources of Negara Brunei Darussalam. Syabas.

Sapin, François. 2010. Impact du couple érosion/sédimentation sur la structuration d'un prisme d'accrétion: L'exemple du prisme NO Bornéo: approche géologique, sismique et thermique. Ph.D. thesis, Paris 6.

Sapin, François, Pubellier, Manuel, Ringenbach, Jean-Claude, \& Rives, Thierry. 2009. The Brunei fold-and-thrust belt: Tectonically-or Gravity driven. Pages 4-9 of: AAPG Hedberg Conference "Deepwater fold and thrust belts" Oct.

Sapin, François, Pubellier, Manuel, Lahfid, Abdeltif, Janots, Dominik, Aubourg, Charles, \& Ringenbach, Jean-Claude. 2011. Onshore record of the subduction of a crustal salient: example of the NW Borneo Wedge. Terra Nova, 23(4), 232-240.

Sapin, François, Ringenbach, Jean-Claude, Rives, Thierry, \& Pubellier, Manuel. 2012. Counter-regional normal faults in shale-dominated deltas: Origin, mechanism and evolution. Marine and Petroleum Geology, 37(1), 121-128.

Sapin, Francois, Hermawan, Iwan, Pubellier, Manuel, Vigny, Christophe, \& Ringenbach, Jean-Claude. 2013. The recent convergence on the NW Borneo Wedge - a crustal-scale gravity gliding evidenced from GPS. Geophysical Journal International, 193(2), 549-556.

Sassi, William, Graham, Rod, Gillcrist, Ralph, Adams, Mike, \& Gomez, Ramon. 2007. The impact of deformation timing on the prospectivity of the Middle Magdalena sub-thrust, Colombia. Geological Society, London, Special Publications, 272(1), 473-498.

Schultz-Ela, DD. 2001. Excursus on gravity gliding and gravity spreading. Journal of Structural Geology, 23(5), 725-731.

Smart, Kevin J, Ferrill, David A, Morris, Alan P, \& McGinnis, Ronald N. 2012. Geomechanical modeling of stress and strain evolution during contractional fault-related folding. Tectonophysics, 576, 171-196.

Souloumiac, P, Leroy, YM, Maillot, B, \& Krabbenhøft, K. 2009. Predicting stress distributions in 
fold-and-thrust belts and accretionary wedges by optimization. Journal of Geophysical Research: Solid Earth, 114(B9).

Suppe, John. 2007. Absolute fault and crustal strength from wedge tapers. Geology, 35(12), 1127-1130.

Swarbrick, RE, Osborne, MJ, \& Yardley, GS. 2002. The magnitude of overpressure from generating mechanisms under realistic basin conditions. AAPG Memoir, 76, 1-12.

Taylor, Brian, \& Hayes, Dennis E. 2013. Origin and History of the South China Sea Basin. American Geophysical Union. Pages 23-56.

Thibaut, Muriel, Jardin, Anne, Faille, Isabelle, Willien, Françoise, \& Guichet, Xavier. 2014. Advanced workflows for fluid transfer in faulted basins. Oil \& Gas Science and Technology-Revue d'IFP Energies nouvelles, 69(4), 573-584.

Tingay, Mark R. P., Hillis, Richard R., Swarbrick, Richard E., Morley, Chris K., \& Damit, Abdul Razak. 2009. Origin of overpressure and pore-pressure prediction in the Baram province, Brunei. AAPG Bulletin, 93(1), 51-74.

Tingay, Mark Robert Paul. 2003. In situ stress and overpressures of Brunei Darussalam. Ph.D. thesis, University of Adelaide, National Centre for Petroleum Geology and Geophysics.

Tingay, Mark RP, Morley, Chris K, Laird, Andrew, Limpornpipat, Orapan, Krisadasima, Kanjana, Pabchanda, Suwit, \& Macintyre, Hamish R. 2013. Evidence for overpressure generation by kerogen-to-gas maturation in the northern Malay Basin. AAPG bulletin, 97(4), 639-672.

Tongkul, Felix. 1991. Tectonic evolution of Sabah, Malaysia. Journal of Southeast Asian Earth Sciences, 6(3-4), 395-405.

Van Rensbergen, Pieter, Morley, CK, Ang, DW, Hoan, TQ, \& Lam, NT. 1999. Structural evolution of shale diapirs from reactive rise to mud volcanism: 3D seismic data from the Baram delta, offshore Brunei Darussalam. Journal of the Geological Society, 156(3), 633-650.

Vendeville, Bruno, \& Cobbold, Peter R. 1988. How normal faulting and sedimentation interact to produce listric fault profiles and stratigraphic wedges. Journal of structural Geology, 10(7), 649659 . 
Wang, Kelin, \& Hu, Yan. 2006. Accretionary prisms in subduction earthquake cycles: The theory of dynamic Coulomb wedge. Journal of Geophysical Research: Solid Earth, 111(B6), n/a-n/a. B06410.

Xiao, Hong-Bin, Dahlen, F. A., \& Suppe, John. 1991. Mechanics of extensional wedges. Journal of Geophysical Research: Solid Earth, 96(B6), 10301-10318.

Yuan, X. P., Leroy, Y. M., \& Maillot, B. 2015. Tectonic and gravity extensional collapses in overpressured cohesive and frictional wedges. Journal of Geophysical Research: Solid Earth, 120(3), 1833-1854. 2014JB011612.

Yuan, Xiaoping. 2016. Extensional collapses in the overpressured frictional upper crust based on limit analysis. Ph.D. thesis, Ecole Normale Supérieure, Laboratoire de Géologie, Paris.

Yuan, XP, Leroy, YM, \& Maillot, B. 2016. Reappraisal of gravity instability conditions for offshore wedges: consequences for fluid overpressures in the Niger Delta. Geophysical Journal International, 208(3), 1655-1671. 


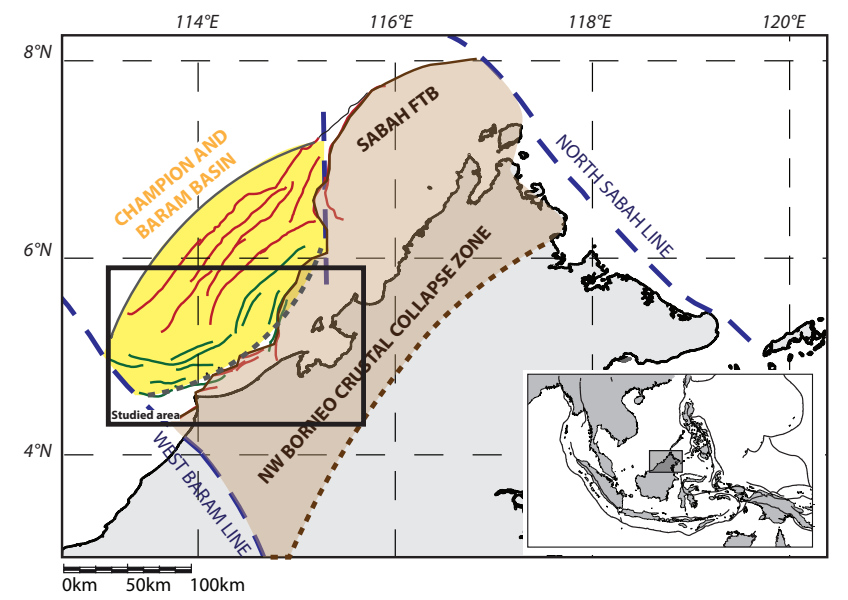

Figure 1: NW Borneo tectonic map [modified from Sapin et al. [2013]; Pubellier et al. [2017]]. The light brown represents the crustal-scale collapse zone described by Sapin et al. [2013], and in the yellow region is observed the deltaic gravity-driven deformations of the Champion and Baram basin. The studied area (black frame) is centered in the offshore Brunei (see Figure 2a for details) 
(a))

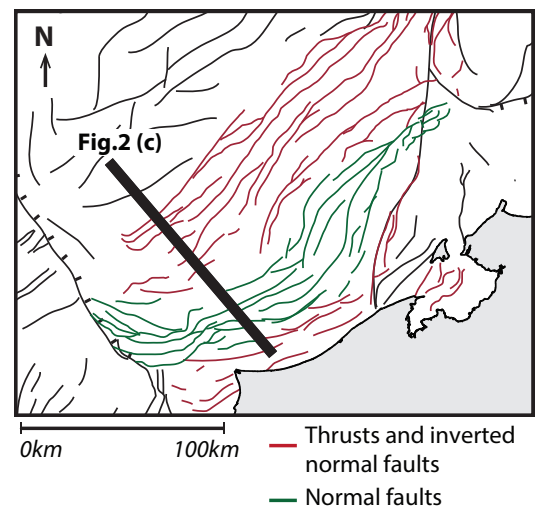

b)

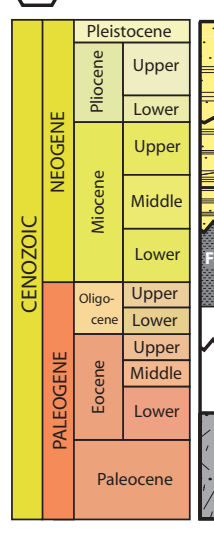

Lithostratigraphy

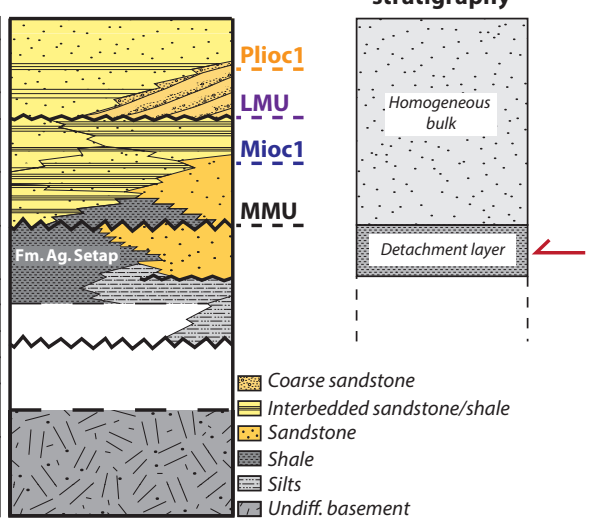
Inverted province $\underset{\mathrm{SE}}{\longleftrightarrow}$

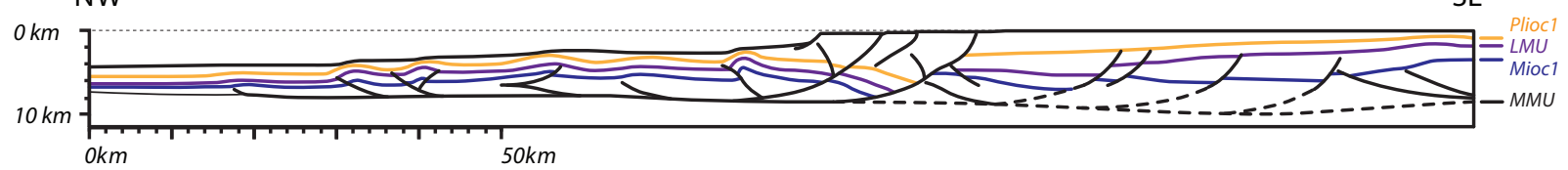

Figure 2: Cenozoic stratigraphy and interpreted seismic section of the southern part of the Brunei margin. a) Tectonic map of the Baram-Champion Delta and position of the selected cross-section. b) Brunei lithostratigraphy [modified from Pubellier et al. [2017]] and interpreted mechanical stratigraphy. c) Depth-converted interpreted seismic section of the southern Brunei margin (modified from Sapin et al. [2009]). Coloured lines correspond to three well-observed seismic horizons named here Mioc1, LMU and Plioc1 


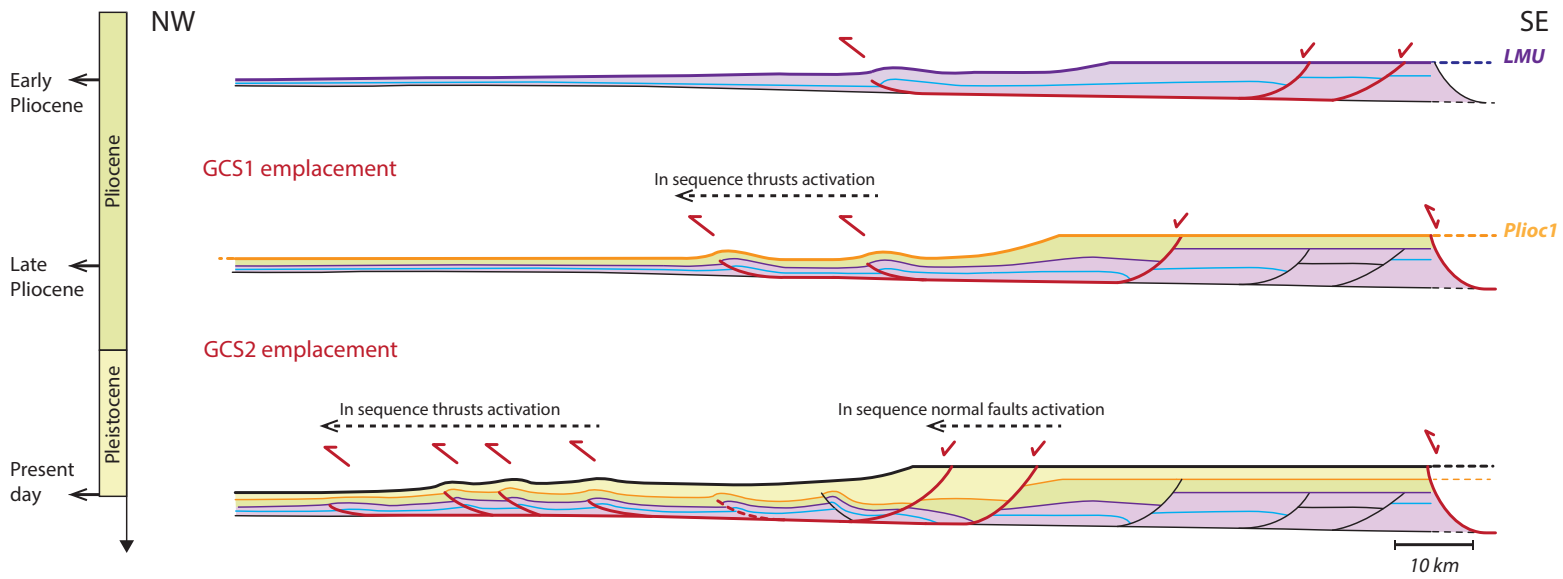

Figure 3: Schematic geological evolution of the deformation of the southern part of the Brunei margin from the Pliocene to present-day time. Two gravitational collapse system (GCS) are successively emplaced since the Late Pliocene. 


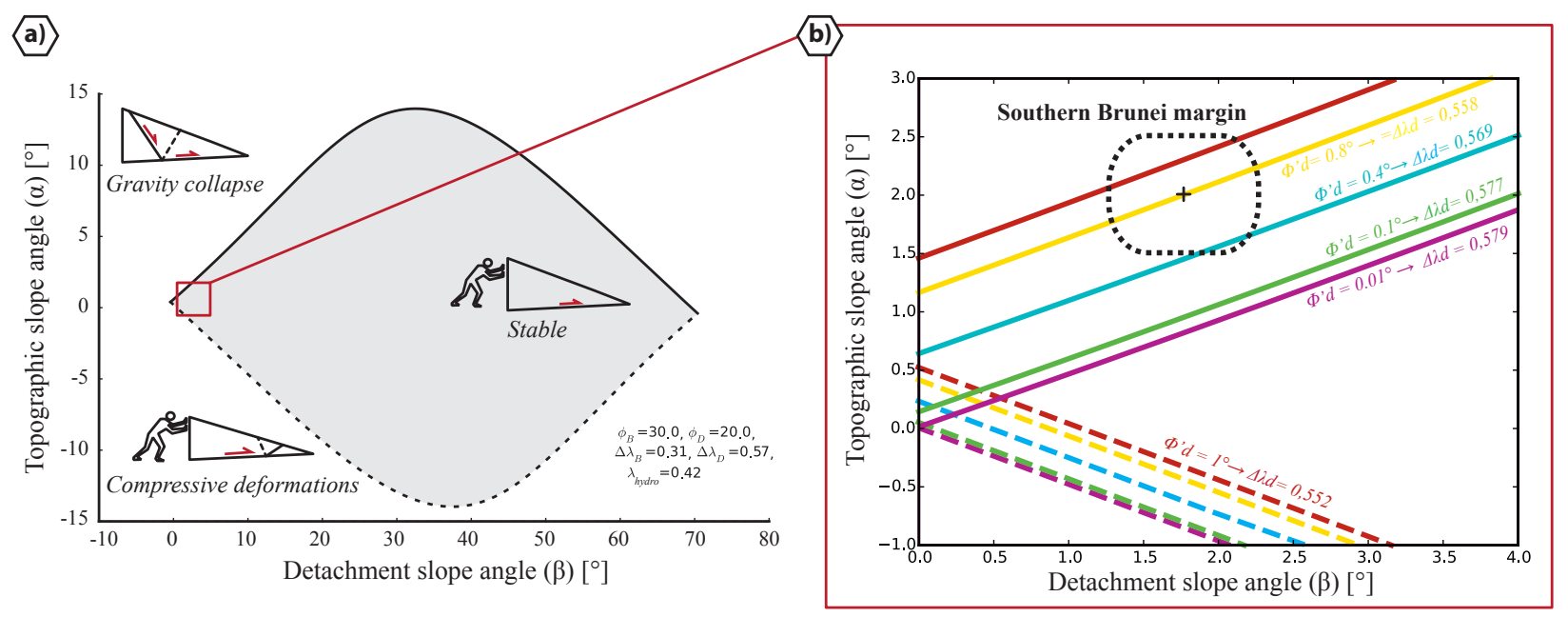

Figure 4: The critical wedge theory applied on the present-day cross section. a) The critical limit in compression (dashed line) and gravitational collapse (full line) is displayed as function of the topographic slope $\alpha$ and the detachment $\operatorname{dip} \beta$, for friction angles of $\phi_{b, d}=30,20^{\circ}$ respectively, a hydrostatic fluid pressure ratio $\lambda_{\text {hydro }}=0.42$ and an overpressure ratio $\Delta \lambda_{b, d}=0.31,0.57$ respectively. In (b) a zoom with envelopes for various values of effective detachment friction angles $\phi_{d}^{\prime}$ (purple: $\phi_{d}^{\prime}=0.01^{\circ}$; green: $0.1^{\circ}$; blue: $0.4^{\circ}$; yellow: $0.8^{\circ}$ and red: $1^{\circ}$. The mean value of $\alpha\left(2^{\circ}\right)$ and $\beta\left(1.8^{\circ}\right)$ measured from the cross-section in Figure $10 \mathrm{c}$ is represented by a cross, surrounded by $0.5^{\circ}$ standard deviation. 


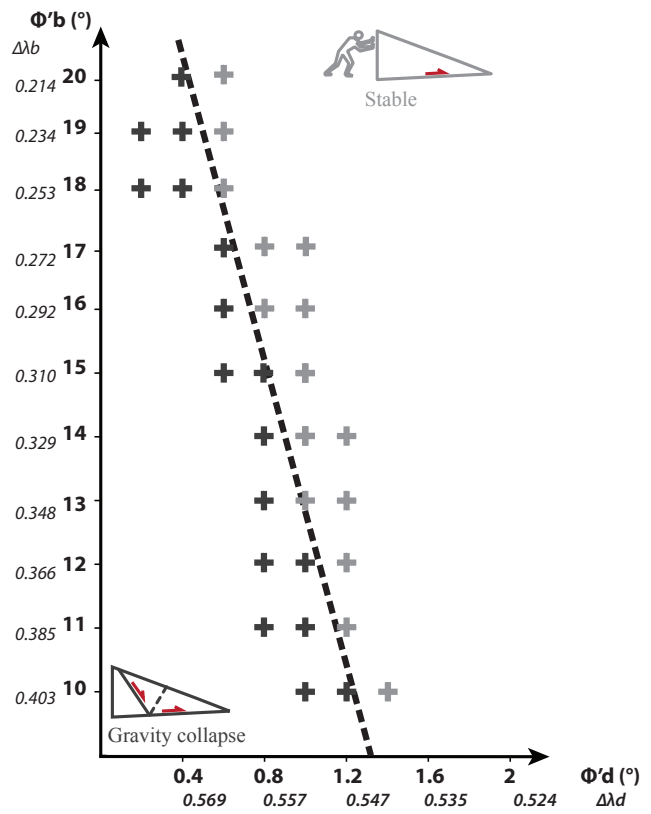

Figure 5: Critical limit between the gravitational collapse domain and the stable wedge domain in the effective friction angle for the bulk and detachment space $\left(\phi_{b}^{\prime}, \phi_{d}^{\prime}\right)$, calculated for a topographic slope $\alpha=2^{\circ}$, a detachment slope $\beta=1.8^{\circ}$, a detachment friction angle $\phi_{d}=10^{\circ}$, a bulk friction angle $\phi_{b}=20^{\circ}$ and a hydrostatic fluid pressure ratio $\lambda_{\text {hydro }}=0.42$. Black crosses represent a tested set of parameters in which gravitational collapse is predicted, whereas grey crosses represent a tested set of parameters in which the wedge remains stable. Both domains are separated by a linear limit strongly dependent on $\phi_{d}^{\prime}$. 


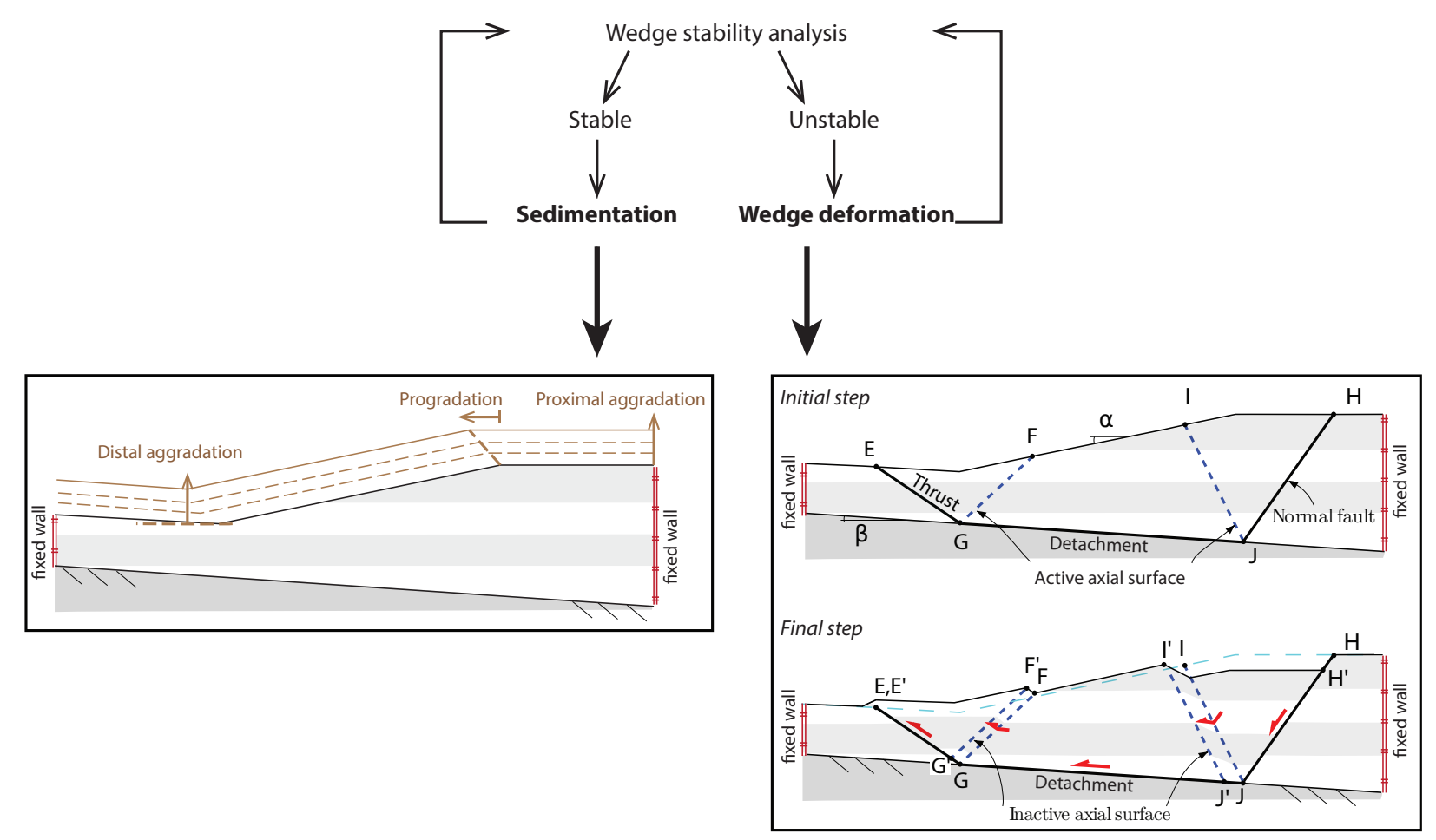

Figure 6: The SLAMTec algorithm. If the wedge is stable (according to Limit Analysis), an increment of sedimentation is applied according to the three parameters (progradation and aggradation). If gravitational collapse is detected, optimal thrust and normal fault (represented by the points $\mathrm{H}, \mathrm{I}, \mathrm{J}$ and $\mathrm{F}, \mathrm{E} \mathrm{G}$ ) are determined using the maximum strength theorem, and an increment of slip is applied to modify the margin geometry, maintaining bulk volume constant. 


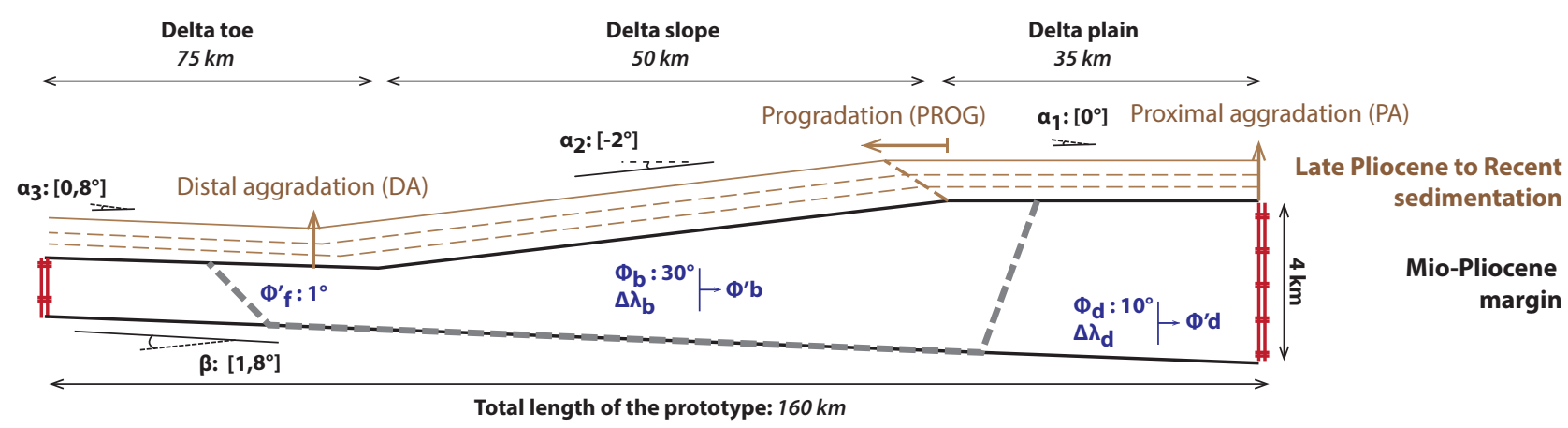

Figure 7: Geometry of the prototype used for the calculation (not to scale) and values of the mechanical parameters that remain constant throughout the study (bulk friction angles $\phi_{b}$, detachment friction angle $\phi_{d}$ and effective fault friction $\phi_{f}^{\prime}$ ). The displacement vectors of the topographic surface associated with each sedimentation parameter are also displayed. 

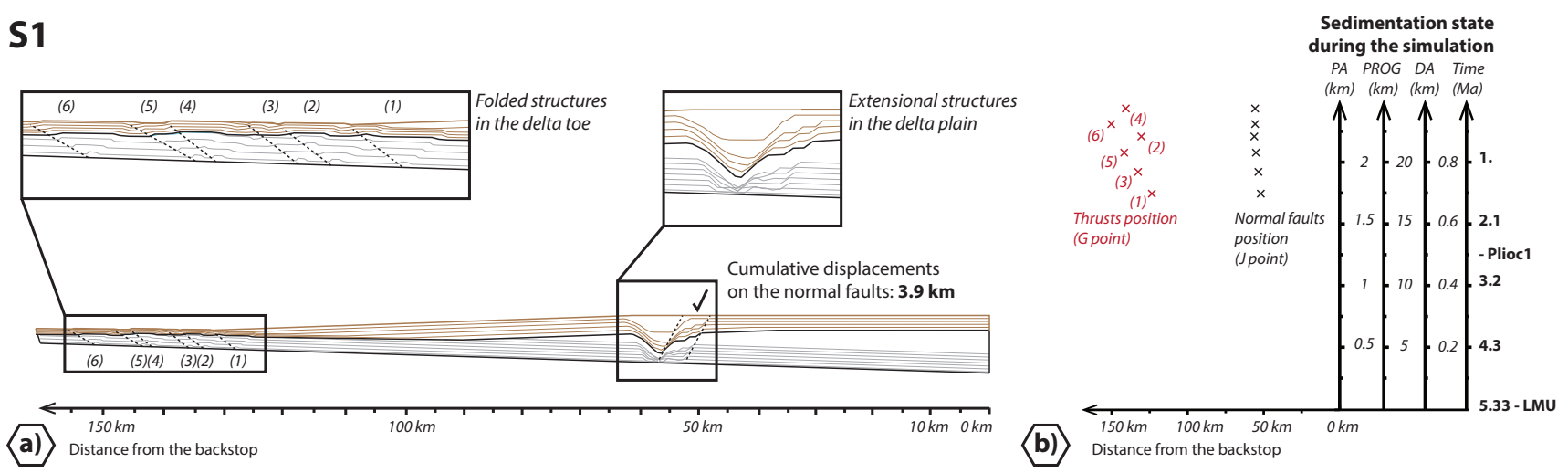

Figure 8: Simulation S1. a) Final geometry of the prototype (in 1:1). Grey lines correspond to pre-LMU terrains, and light brown lines correspond to sedimentation during the simulation. Six faults occured in the compressive region, forming four distinct folds. b) Position of the points $\mathrm{G}$ and $\mathrm{J}$ through time (Figure 6 ) in red and black respectively. Thrusts position during sedimentation determines an overall in-sequence trend of fold development, with some out-ofsequence re-activations. 
(a) $\mathbf{S 2}$

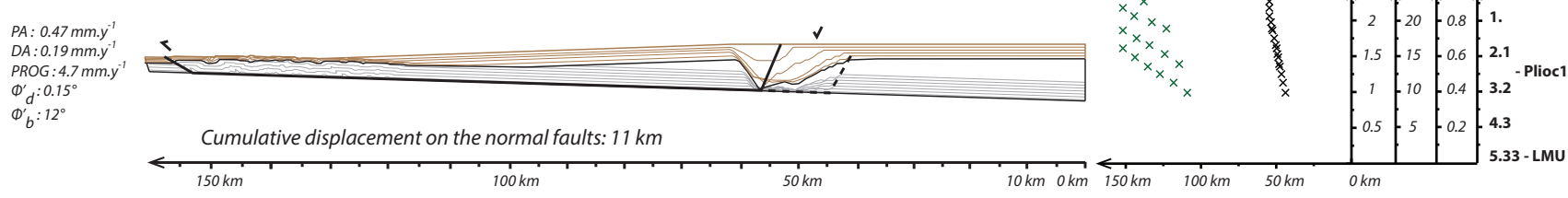

(b) 53
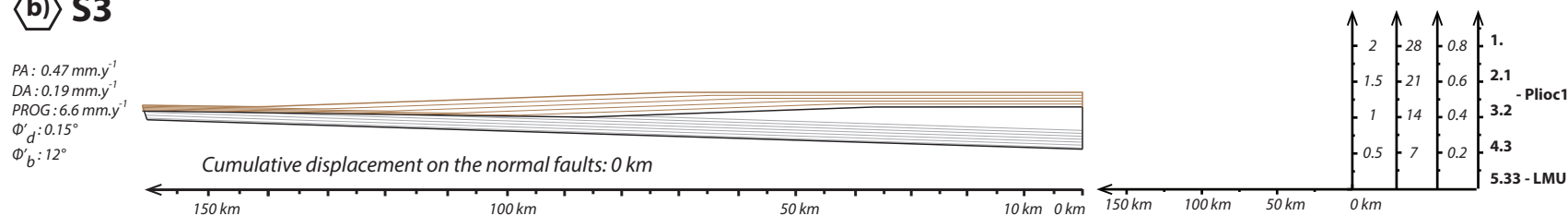

(c) 54

$P A: 0.66 \mathrm{~mm} . y^{\prime \prime}$ DA: $0.19 \mathrm{~mm} \cdot \mathrm{y}^{-1}$ PROG: $4.7 m$ $\Phi_{d}^{\prime}: 0.15^{\circ}$
$\Phi_{b}^{\prime}: 12^{\circ}$

$$
<
$$
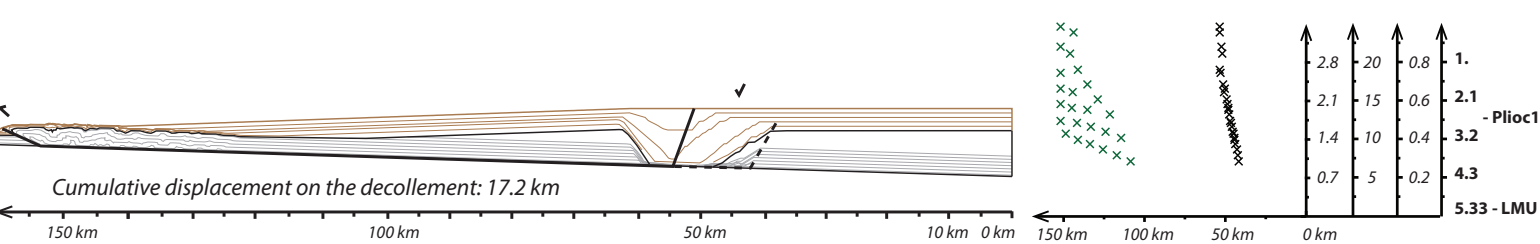

(d) $\mathrm{S5}$
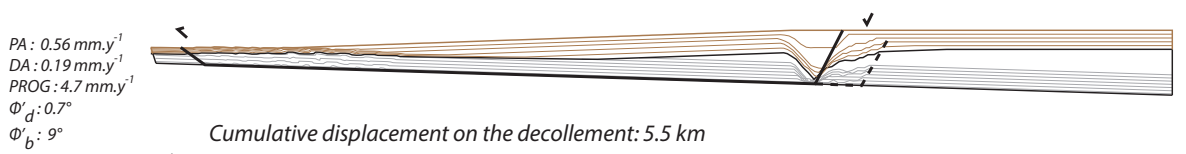
Cumulative displacement on the decollement: $5.5 \mathrm{~km}$
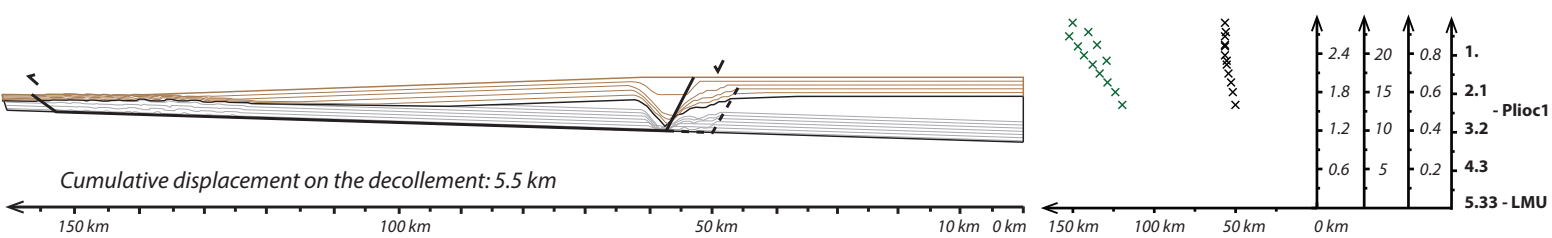

\section{(e) 56}
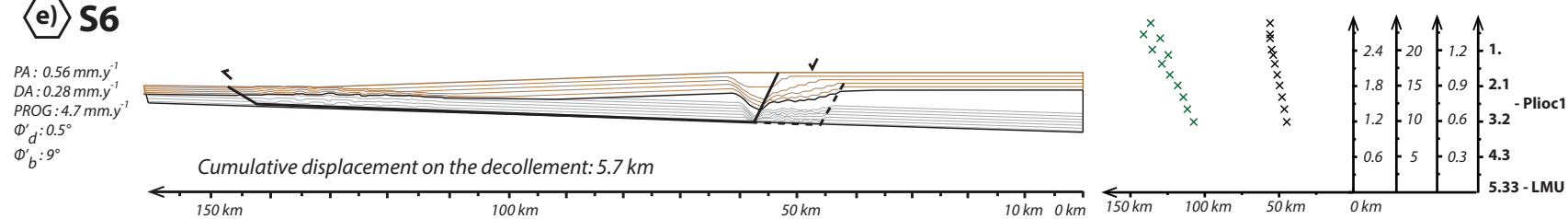

Figure 9: Final geometry and evolution of the $\mathrm{G}$ and $\mathrm{J}$ points (respectively the position of the thrust and the normal fault on the detachment, see Figure 6) in the simulations S2 (a) to S6 (e) (in 1:1). In the G-J grams displaying the evolution of the G-J points position with the sedimentation, black crosses correspond to J points and green crosses correspond to $G$ points. PArate is the proximal aggradation rate, DArate the distal aggradation rate, PROG the progradation rate, $\phi_{d}^{\prime}$ the detachment effective friction angle and $\phi_{b}^{\prime}$ the bulk effective friction angle. 
(4) Two distincts GCS

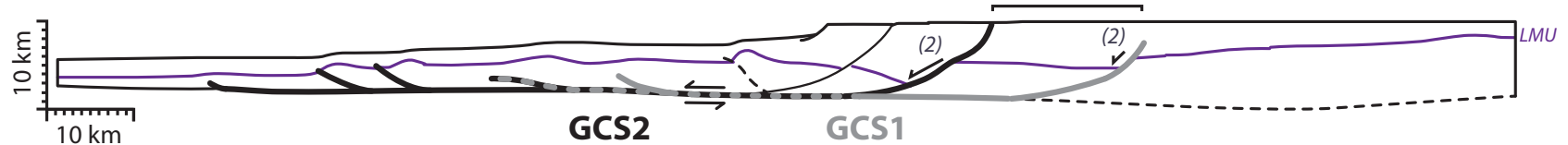

Figure 10: Scaled structural cross-section illustrating the criteria used to compare the simulations with the geological observations. They are, in inclusive order: (1) the collapse of the margin, (2) the cumulative extensional slip on the normal faults, (3) the length of the deformed system and (4) the existence of two distinct gravitational collapse system (GCS). The LMU limit is represented by a purple horizon. 


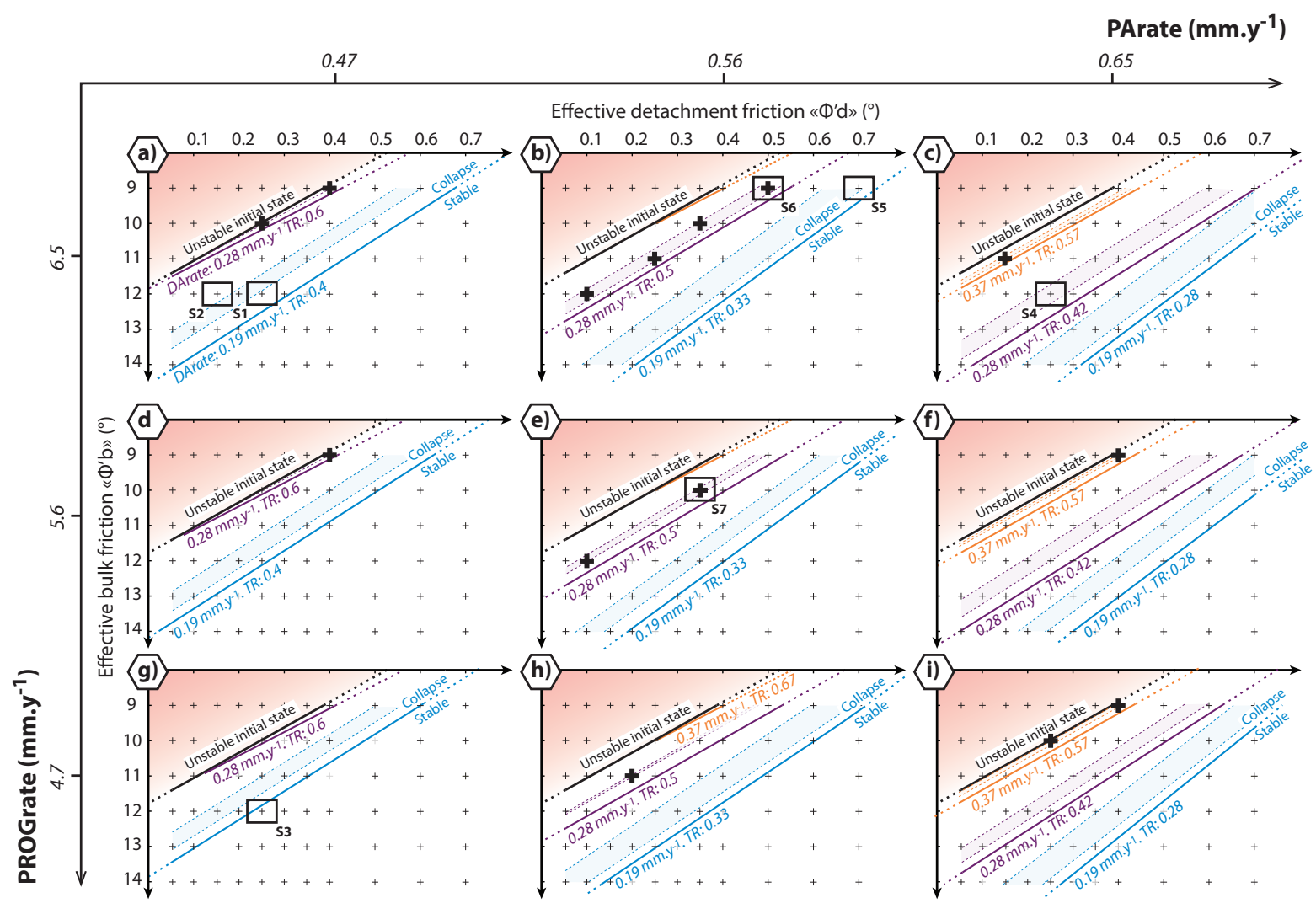

Figure 11: Results of the parameter selection. Crosses located between the black solid line and a coloured solid line yield simulations that obey the first criterion. Blue, purple and orange lines represent respectively the results for the distal aggradation rates DArate $=0.19,0.28$ and $0.37 \mathrm{~mm} . \mathrm{y}^{-1}$. Crosses within the coloured ranges delimited by dashed lines fit the criterions 1 and 2. Bold crosses fit criteria 1,2 and 3. No simulations fits the criterion 4. Values of the four other parameters are indicated on the axes, so that all results are represented in nine graphs a), b) c), d), e), f), g), h) and i). The value of the thickness ratio TR is displayed for each set of sedimentation parameters below the DArate coloured lines. The position of the simulations $\mathrm{S} 1$ to $\mathrm{S} 7$ on the graphs are also framed. PArate is the proximal aggradation rate, PROGrate the progradation rate. 


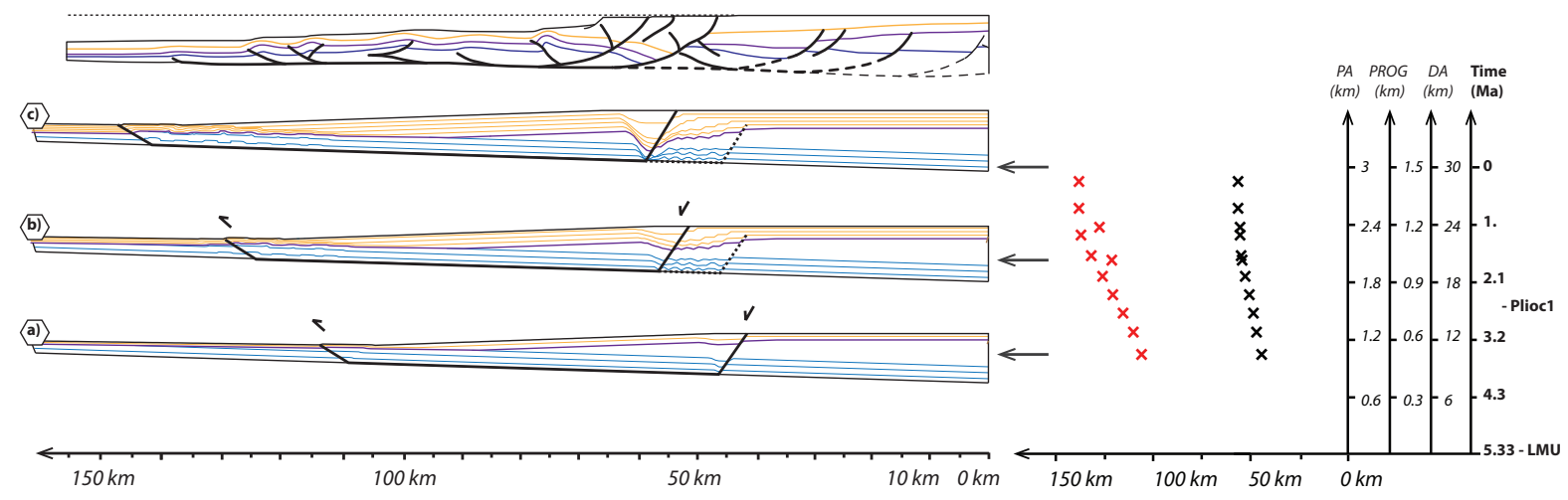

Figure 12: Geometry (in 1:1) of the simulation S7 and evolution of the G-J points position on the detachment in this simulation, defined as one of 14 simulations that match the best the cross-section. The geological cross-section is displayed above for comparison. In a), the simulated cross-section is shown at 3.4 Ma., at the starting point of the collapse. In b), crosssection at 1.6 Ma, during the out-of-sequence thrusting deformation style. In c), the final step of sedimentation. Faults with displacement vectors indicate that active faulting occurred at the displayed time-step. Dashed black lines indicate the position of the first normal fault. In the G-J gram to the right, displaying the evolution G-J points position, recall that black crosses and red crosses correspond to the roots of the normal faults and thrusts on the detachment, respectively. PA is the amount of proximal aggradation at a given sedimentation step, DA the amount of distal aggradation at a given sedimentation step and PROG the amount of progradation at a given sedimentation step. 


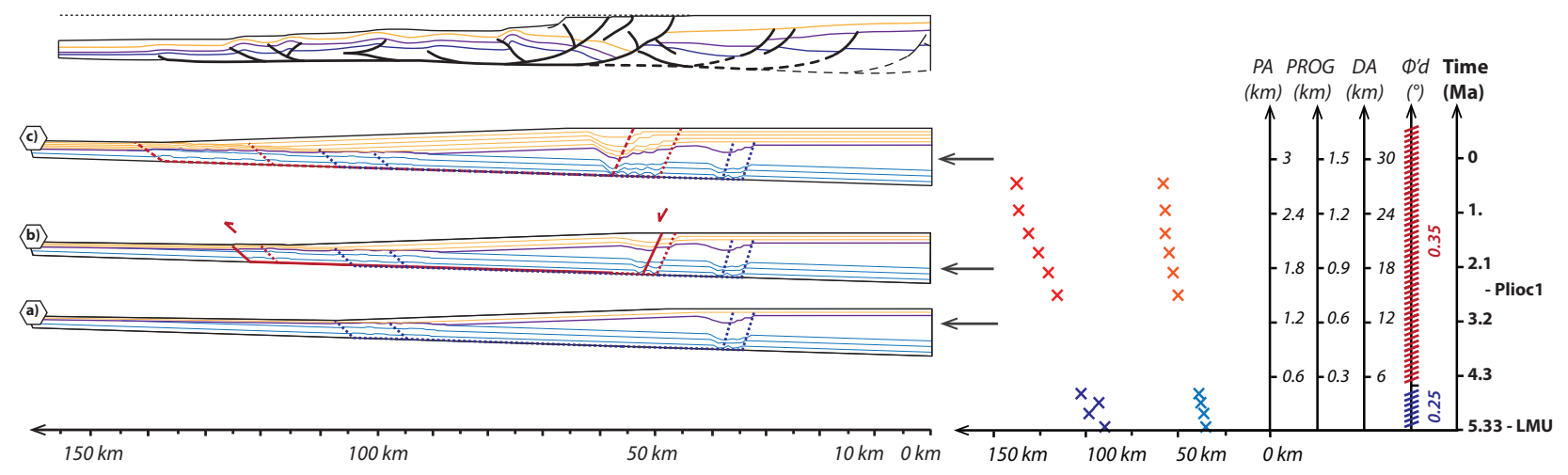

Figure 13: Geometry of the simulation S8, and evolution of the G-J points position on the detachment in this simulation, designed to reproduce two distinct gravitational collapse systems (GCS). The geological cross-section is displayed above for comparison. In a), the simulated cross-section at 3.2 Ma, after sealing of the GCS1 (in blue). In b), the cross-section at $2 \mathrm{Ma}$, during the collapse of GCS2 (in red). In c), the cross-section at the end of the simulation. In the G-J gram, displaying the evolution G-J points position, light blue and dark blue crosses correspond to GCS1 normal faults and thrusts position on the detachment, while light red and dark red crosses correspond to GCS2 normal faults and thrusts positions on the detachment. $\mathrm{PA}$ is the amount of proximal aggradation at a given sedimentation step, DA the amount of distal aggradation at a given sedimentation step, PROG the amount of progradation at a given sedimentation step and $\phi_{d}^{\prime}$ the detachment effective friction angle. 


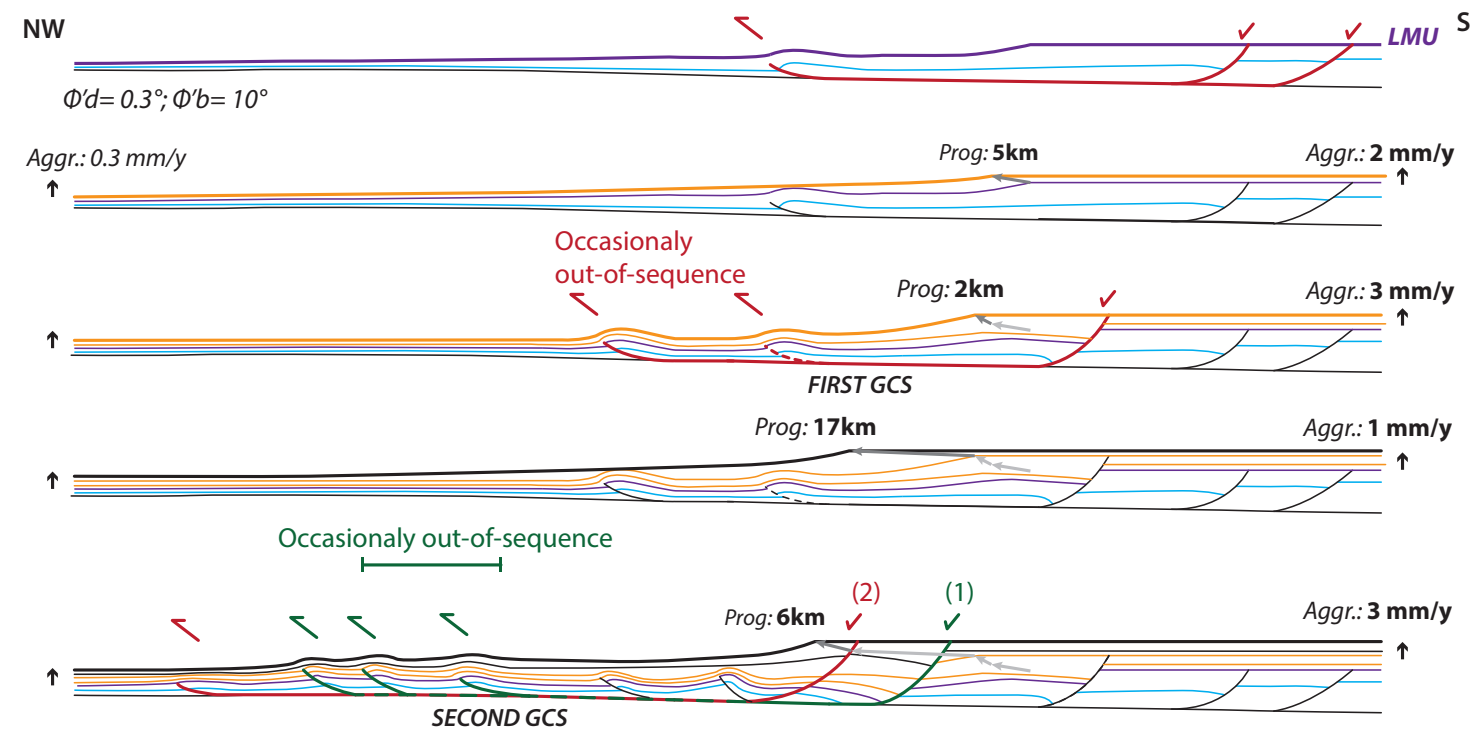

(1) Progradation of the deltaic system

(2) Aggradation of the deltaic system

Late Pliocene

(3) Very fast progradation of the deltaic system

(4) Aggradation of the deltaic system

Present day

\section{b) Constant sedimentation model hypothesis}

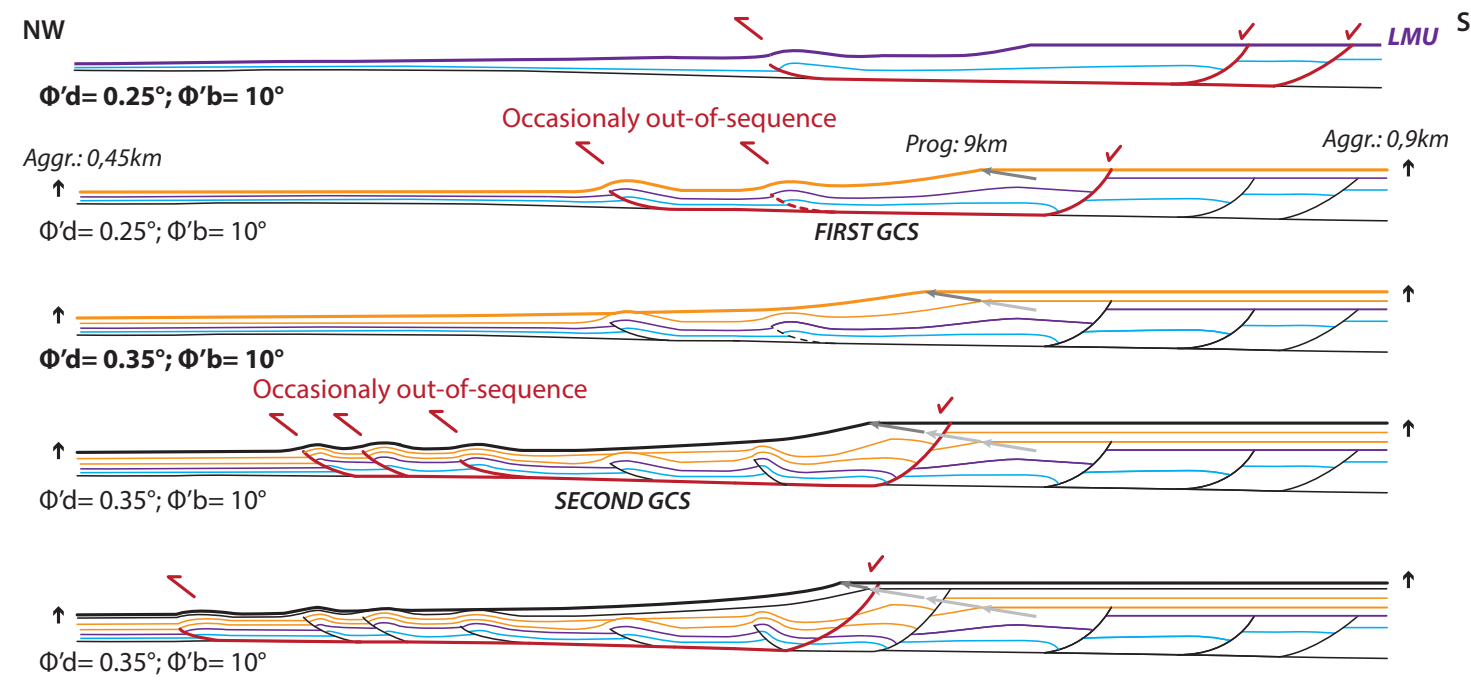

Early Pliocene

(1) High fluids overpres sure in the decollement

(2) Fluids overpressure

Late Pliocene

(3) Differential sediment loading $(T R<1)$

(4) Progradation of the gravity collapse system

Present day

Figure 14: End-member schematic geological evolution of the deformation of the southern part of the Brunei margin from the Pliocene to recent time, including the sedimentation and effective frictions values necessary to mechanically validate the section evolution. In red and green is shown the active gravitational collapse system (GCS). a) Evolution of the margin assuming a constant fluid overpressure. Major changes in the progradation and aggradation of the Baram delta lead to alternating stability and collapse periods. In recent times, the progradation of the deformation in the second GCS is represented by green and red lines. b) Evolution of the margin assuming a constant sedimentation pattern, inspired from S8. A drop in the detachment fluid overpressure stabilises the margin until the differential sediment supply (the thickness ratio TR $<1$ ) destabilises it again, forming the second GCS. $\phi_{d}^{\prime}$ is the detachment effective friction angle, $\phi_{b}^{\prime}$ the bulk effective friction angle, "prog" the amount progradation at a given time-step and "aggr." the amount of aggradation at a given time-step. 


\begin{tabular}{|c|c|c|c|c|c|c|c|c|c|c|c|}
\hline $\begin{array}{l}\text { Sim } \\
\text { Nbr. }\end{array}$ & $\Delta \lambda_{d}$ & $\begin{array}{c}\phi_{d}^{\prime}\left(\phi_{d}=\right. \\
\left.10^{\circ}\right)\end{array}$ & $\Delta \lambda_{b}$ & $\begin{array}{c}\phi_{b}^{\prime} \\
\left(\phi_{b}=30^{\circ}\right)\end{array}$ & $\mathrm{PA}$ & DA & PROG & $\begin{aligned} & \mathrm{TR} \\
= & \mathrm{DA} / \mathrm{PA}\end{aligned}$ & PArate & DArate & PROGrate \\
\hline & - & & - & & $\mathrm{km}$ & $\mathrm{km}$ & $\mathrm{km}$ & - & $m m \cdot y^{-1}$ & $m m \cdot y^{-1}$ & $m m \cdot y^{-1}$ \\
\hline S1 & 0.567 & 0.25 & 0.367 & 12 & 2.5 & 1 & 25 & 0.4 & 0.47 & 0.19 & 4.7 \\
\hline $\mathrm{S} 2$ & 0.571 & 0.15 & 0.367 & 12 & 2.5 & 1 & 25 & 0.4 & 0.47 & 0.19 & 4.7 \\
\hline S3 & 0.567 & 0.25 & 0.367 & 12 & 2.5 & 1 & 35 & 0.4 & 0.47 & 0.19 & 6.5 \\
\hline S4 & 0.567 & 0.25 & 0.367 & 12 & 3.5 & 1 & 25 & 0.28 & 0.66 & 0.19 & 4.7 \\
\hline S5 & 0.551 & 0.7 & 0.420 & 9 & 3 & 1 & 25 & 0.33 & 0.56 & 0.19 & 4.7 \\
\hline S6 & 0.540 & 0.5 & 0.420 & 9 & 3 & 1.5 & 25 & 0.5 & 0.56 & 0.28 & 4.7 \\
\hline $\begin{array}{l}\text { Param } \\
\text { study }\end{array}$ & $\begin{array}{l}0.577- \\
0.540\end{array}$ & $0.05-0.7$ & $\begin{array}{l}0.310- \\
0.420\end{array}$ & $9-15$ & $\begin{array}{c}2.5, \\
3, \\
3.5\end{array}$ & $\begin{array}{c}1, \\
1.5, \\
2\end{array}$ & $\begin{array}{l}25, \\
30 \\
35\end{array}$ & $\bullet$ & $\begin{array}{l}0.47 \\
0.56 \\
0.65\end{array}$ & $\begin{array}{l}0.19 \\
0.28, \\
0.37\end{array}$ & $\begin{array}{l}4.7, \\
5.6, \\
6.4\end{array}$ \\
\hline S7 & 0.560 & 0.35 & 0.403 & 10 & 3 & 1.5 & 30 & 0.5 & 0.56 & 0.28 & 5.6 \\
\hline S8 & $\begin{array}{l}0.566 \\
\text { then } \\
0.560\end{array}$ & $\begin{array}{c}0.25 \text { then } \\
0.35\end{array}$ & 0.403 & 10 & 3 & 1.5 & 30 & 0.5 & 0.56 & 0.28 & 5.6 \\
\hline
\end{tabular}

Table 1: Mechanical and sedimentation parameters used in SLAMTec simulations. $\Delta \lambda_{d}$ is the detachment overpressure ratio, $\phi_{d}^{\prime}$ the detachment effective friction angle, $\phi_{d}$ the detachment friction angle, $\Delta \lambda_{b}$ the bulk overpressure ratio, $\phi_{b}^{\prime}$ the bulk effective friction angle, $\phi_{b}$ the bulk friction angle, PA the total amount of proximal aggradation in the simulation, DA the total amount of distal aggradation in the simulation, PROG the total amount of progradation in the simulation, TR the thickness ratio of the simulation, PArate the rate of proximal aggradation in $m m \cdot y^{-1}$, DArate the rate of distal aggradation in $m m \cdot y^{-1}$, PROGrate the rate of progradation in $m m \cdot y^{-1}$. 